\title{
A Review on Nanomaterial Dispersion, Microstructure, and Mechanical Properties of Carbon Nanotube and Nanofiber Reinforced Cementitious Composites
}

\author{
Shama Parveen, ${ }^{1}$ Sohel Rana, ${ }^{1}$ and Raul Fangueiro, ${ }^{1,2}$ \\ ${ }^{1}$ Fibrous Materials Research Group (FMRG), School of Engineering, University of Minho, 4800-058 Guimaraes, Portugal \\ ${ }^{2}$ Department of Civil Engineering, University of Minho, 4800-058 Guimaraes, Portugal \\ Correspondence should be addressed to Sohel Rana; soheliitd2005@gmail.com
}

Received 11 March 2013; Accepted 28 May 2013

Academic Editor: Tianxi Liu

Copyright (C) 2013 Shama Parveen et al. This is an open access article distributed under the Creative Commons Attribution License, which permits unrestricted use, distribution, and reproduction in any medium, provided the original work is properly cited.

Excellent mechanical, thermal, and electrical properties of carbon nanotubes (CNTs) and nanofibers (CNFs) have motivated the development of advanced nanocomposites with outstanding and multifunctional properties. After achieving a considerable success in utilizing these unique materials in various polymeric matrices, recently tremendous interest is also being noticed on developing $\mathrm{CNT}$ and CNF reinforced cement-based composites. However, the problems related to nanomaterial dispersion also exist in case of cementitious composites, impairing successful transfer of nanomaterials' properties into the composites. Performance of cementitious composites also depends on their microstructure which is again strongly influenced by the presence of nanomaterials. In this context, the present paper reports a critical review of recent literature on the various strategies for dispersing CNTs and CNFs within cementitious matrices and the microstructure and mechanical properties of resulting nanocomposites.

\section{Introduction}

Civil infrastructures are the building blocks of any country's highway structures, bridges, pavements, runways for airport, and so forth, and concrete is the primary material for their construction. Concrete generally consists of Ordinary Portland Cement (OPC, which is known as the principal binding agent), coarse aggregates, and fillers such as sand, admixtures, and water. Cementitious materials are characterized by quasi-brittle behaviour and are susceptible to cracking. The cracking process within concrete begins with isolated nanocracks, which then conjoin to form microcracks and in turn macrocracks. Reinforcement is required because of this brittle nature of concrete, and as reinforcements, polymeric fibers as well as glass and carbon fibers were used during the 1970s, 80s, and 90s, respectively [1]. Recently, the use of microfiber reinforcements has led to significant improvement in the mechanical properties of cement-based materials by delaying the transformation of microcracks into macroforms, but they could not stop the crack growth. This fact encouraged the use of nanosize fibers or particles for concrete reinforcement in order to prevent the transformation of nanocracks into microcracks [2, 3]. Nanoparticle addition to cement paste was found to improve mechanical, chemical, and thermal properties of cementitious matrix. There are various types of nanoparticles, especially $\mathrm{SiO}_{2}$ and $\mathrm{Fe}_{2} \mathrm{O}_{3}$, which when incorporated into cement led to considerable improvement in the compressive strength [49]. Nanosized $\mathrm{TiO}_{2}$ has been added to accelerate the rate of hydration and increase the degree of hydration [10]. Moreover, the photocatalytic characteristic of $\mathrm{TiO}_{2}$ helped to remove the organic pollutants from concrete surfaces, which were directly exposed to UV radiation [11]. Carbon nanomaterials present a large group of functional materials with exceptional physical properties. Extensive research endeavors over the last few years demonstrated the application potential of various carbon nanomaterials, mainly carbon nanofiber (CNF) and carbon nanotube (CNT), in polymeric matrices. This fact has motivated the scientists and researchers worldwide to use these nanomaterials in concrete as well, in order to utilize their extraordinary mechanical, electrical, and thermal properties [12, 13]. In addition to 
that, in nanometer length scale, CNFs and CNTs offer the possibility to restrict the formation as well as growth of nanocracks within concrete, thus creating a new generation of crack-free materials. So, concrete reinforcement using carbon nanomaterials is a rapidly growing research area in recent times. However, there exists a large difference in the structure and chemistry between a polymeric and a cementitious, matrix, and, therefore, a great deal of research activities is being directed towards understanding the interaction between these nanomaterials and cementitious matrices for their successful application.

\section{Structure of Cement}

A dry portion of Portland cement is composed of $63 \%$ calcium oxide, $20 \%$ silica, $6 \%$ alumina, $3 \%$ iron (III) oxide, and small amount of other materials including some impurities. These materials when react with water cause an exothermic reaction forming a mineral glue (known as "C-S-H" gel), calcium hydroxide, ettringite, monosulfate, unhydrated particles, and air voids. Molecular structure of C$\mathrm{S}-\mathrm{H}$ gel was not fully understood till recent past, but some researchers in Massachusetts Institute of Technology (MIT, USA) [14] recently proposed a structure, and according to that, cement hydrate consists of a long chain silica tetrahedral and calcium oxide in long range distances, where water causes an intralayer distortion in otherwise regular geometry (Figure 1). The distortion in the structure due to addition of water makes the cement hydrate robust. The density of $\mathrm{C}-\mathrm{S}-\mathrm{H}$ has been determined as $2.6 \mathrm{~g} / \mathrm{cc}$ [15], and the elastic modulus of different cementitious phases were determined as follows [16]: $35 \mathrm{MPa}$ for the $\mathrm{Ca}(\mathrm{OH})_{2}$ phase, 26 and $16 \mathrm{MPa}$ for high and low stiffness $\mathrm{C}-\mathrm{S}-\mathrm{H}$, respectively, and $10 \mathrm{MPa}$ for the porous phase. One of the major drawbacks of cement structure is its proneness towards crack formation and degradation. The amorphous phase of cement, that is, C-S-H gel, is itself a nanomaterial, and, therefore, the degradation mechanisms within concrete start at nanoscale, spreading then to micro- and macroscales. Degradation of concrete can be due to physical reasons such as abrasion and erosion, freeze thaw cycles, leaching and efflorescence, drying shrinkage, and so forth or chemical reasons such as aggregate-paste reaction, sulfate and acid attack, carbonation, and so forth [17-22].

\section{Carbon Nanomaterials}

After the discovery of buckyball (a ball-like molecule made of pure carbon atoms) in 1985 by Kroto et al. [23], a tubular form of carbon was reported by Iijima [24] in 1991 and named carbon nanotubes (CNTs). These nanotubes (called multiwalled carbon nanotubes or MWCNTs) consisted of up to several tens of graphitic shells with adjacent shell separation of $\sim 0.34 \mathrm{~nm}$, diameters of a few nanometers, and high length/diameter ratio. About two years later, he reported the observations of single-walled carbon nanotubes (SWCNTs), which consist of a single graphite sheet seamlessly wrapped into a cylindrical tube [25], as shown in Figure 2. CNTs can be produced by various techniques such

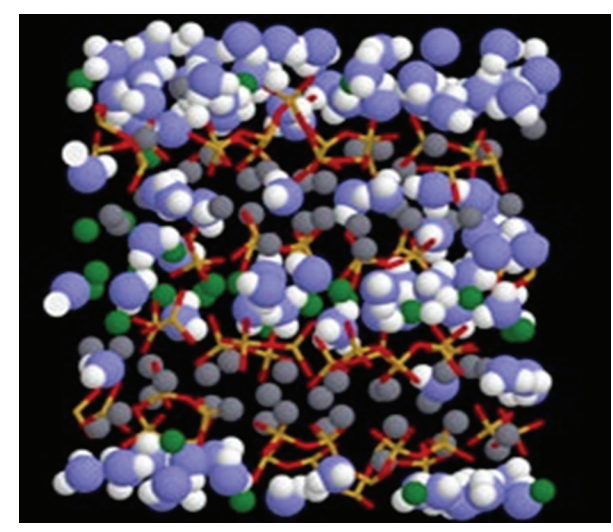

Figure 1: The molecular model of C-S-H: the blue and white spheres are oxygen and hydrogen atoms of water molecules, respectively; the green and gray spheres are inter- and intralayer calcium ions, respectively; the yellow and red sticks are silicon and oxygen atoms in silica tetrahedral [14].

as arc discharge, laser ablation, thermal and plasma enhanced chemical vapor deposition (CVD), and many other recently developed methods [21-34]. CNTs possess outstanding properties such as the highest Young's modulus $(1.4 \mathrm{TPa})$, tensile strength (above $100 \mathrm{GPa}$ ), current density $\left(10^{9} \mathrm{~A} / \mathrm{cm}^{2}\right)$, and thermal conductivity (above $3000 \mathrm{~W} / \mathrm{mK}$ ) among the known materials. Additionally, CNTs are flexible and have high breaking elongation (20-30\%).

Vapour-grown carbon nanofibers (VCNFs) are another type of carbon nanomaterial which was first explored in 1889 by Hughes and Chambers [35], and their hollow graphitic structure was first revealed in the early 1950s by Radushkevich and Lukyanovich [36]. Because of their low production cost and higher availability as compared to CNTs and excellent properties (although lower than CNTs), VCNFs are receiving tremendous research attention in recent times. VCNFs can be synthesized by catalytic CVD of a hydrocarbon (such as natural gas, propane, acetylene, benzene, and ethylene) or carbon monoxide using metal ( $\mathrm{Fe}, \mathrm{Ni}, \mathrm{Co}, \mathrm{Au})$ or metal alloy (Ni-Cu, Fe-Ni) catalysts at a temperature of $500-1500^{\circ} \mathrm{C}$ [37-43]. The dimension and structure of CNF are highly dependent on the manufacturing and post-treatment methods [44]. CNFs are hollow core nanofibers comprising either a single layer [44] or double layer of graphite planes as shown in Figure 3 [45]. The graphite planes can be stacked parallel or at a certain angle from the fiber axis and nested with each other to form different structures such as bamboolike, parallel, and cup-stacked [46-49].

\section{Dispersion of CNTs and CNFs}

Dispersion of CNTs and CNFs is one of the major factors that strongly influence the properties of nanocomposites. These nanomaterials have strong tendency to agglomerate due to presence of attractive forces (Van der Waals), originated from their polarizable extended $\pi$-electron systems. Infiltration of agglomerates with matrices is very difficult, and their presence is therefore the source of potential defects in nanocomposites. The process of deagglomeration and subsequent 


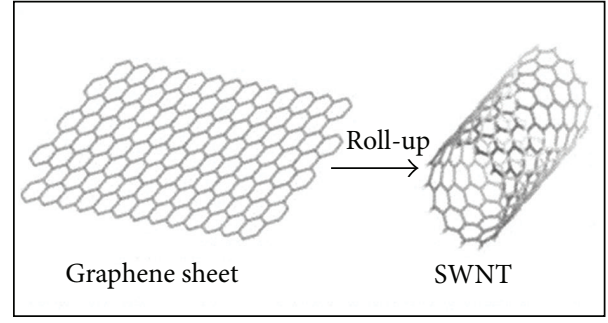

(a)

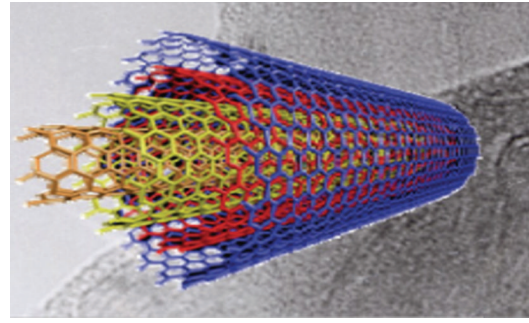

(b)

FIGURE 2: Schematic representation of SWCNT (a) and MWCNT (b) [25].

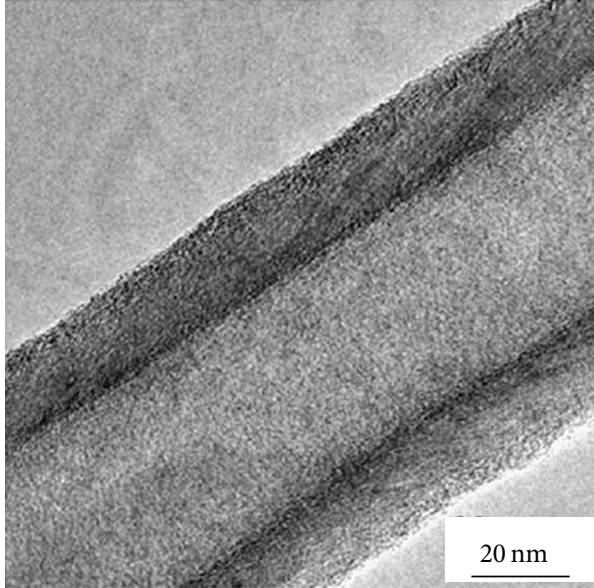

(a)

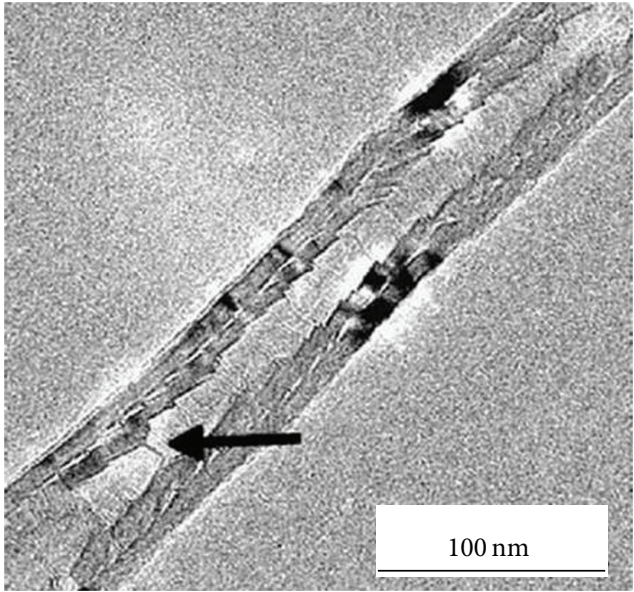

(b)

FIGURE 3: TEM micrograph of CNF showing a single layer (a) and double layer (b) $[44,45]$.

distribution of nanomaterials within matrices or solvents is called dispersion. Dispersion can occur either due to abrupt splitting up of agglomerates into small fragments under high stress (rupture) or due to continuous detachment of small fragments at a comparatively lower stress (erosion). The dispersion behaviour of CNF and CNT depends on a few critical factors such as length of nanomaterials, their entanglement density, volume fraction, matrix viscosity, and attractive forces. Different chemical methods have been tried till date to achieve homogeneous dispersion of carbon nanomaterials in water and various polymers such as using solvents [50], surfactants [51-54], functionalization with acids [55], amines [56], fluorines [57], plasma [58, 59], microwave [60] and matrix moieties [61], noncovalent functionalization [62], using block polymers $[63,64]$, wrapping conjugated polymers [65], and other techniques [66, 67]. On the other hand, the basic physical technique used for carbon nanomaterial dispersion is the ultrasonication, which is often used in combination with the other methods mentioned above [68-74].

\section{Dispersion of CNFs/CNTs in Cementitious Matrices}

Similar to polymeric matrices, dispersion of carbon nanomaterials in cementitious matrices is also a critical issue which strongly influences the properties of cement-based nanocomposites. The approach of dispersing CNF/CNT directly within cement paste during mixing is not feasible, as the thickening of cement paste begins within a short period after addition of water [75]. The mixing process using a Hobart mixer, commonly used to prepare mortar paste, cannot ensure proper dispersion of CNT within cementitious matrix [76], resulting in large CNT clusters within the hydrated paste (Figure 4). To avoid this situation, the strategy commonly employed for mixing CNTs/CNFs with cementitious matrices is to disperse these nanomaterials first in water, followed by mixing of nanomaterial/water dispersion with cement using a conventional mixer. However, the methods of dispersing nanomaterials in water should be carefully selected so that they do not interfere with the hydration and processing of cement nanocomposites. Many surfactants that are successfully used to disperse carbon nanomaterials in polymeric matrices have been reported to create problems in cement hydration, entrap air in the cement paste or react with the water-reducing admixtures [77].

Dispersion of CNF/CNT in cement is even more difficult as compared to the polymeric matrices. One of the reasons for poor dispersion may be the size of cement grains. As CNFs or CNTs are separated by the cement grains, the presence of larger grains than the average leads to absence of CNFs/CNTs in some areas, whereas they can be present in higher quantity 


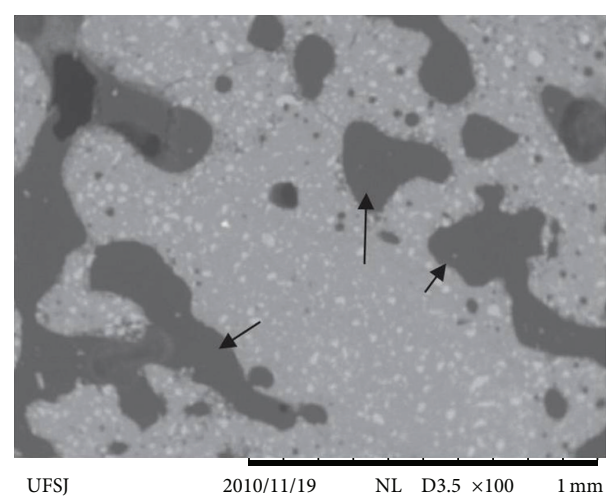

Figure 4: SEM image of CNT/cement paste after hydration [76].

in other areas where the cement grains are much smaller in size [78]. Although reduction of cement particle size using ball milling can improve nanomaterial dispersion, small grain cement has many other disadvantages such as high water consumption, thermal cracking, more chemical and autogenous shrinkage, and so forth [79]. Recently performed 3D simulation study suggested that a homogeneous distribution of nanomaterials within cement is possible only when the cement particles are also distributed homogeneously without any agglomeration [80]. Therefore, to improve carbon nanomaterial dispersion in cementitious matrices various approaches have been employed till date, carefully considering the issues discussed above, and can be broadly categorized into physical and chemical techniques, as discussed in the following sections. However, it should be noted that the various chemical routes (such as using surfactant, polymers, or functionalization) cannot directly disperse nanomaterials in water; instead, they help in the dispersion process by wetting the nanomaterials with water and improving the dispersion stability. Therefore, these chemical routes are always used in combination with the physical routes (such as ultrasonication), which can directly disperse the nanomaterials.

\subsection{Physical Techniques}

5.1.1. Ultrasonication. In an ultrasonic processor, electrical voltage is converted to mechanical vibrations, which are transferred to the liquid medium (water or solvent) and lead to formation and collapse of microscopic bubbles. During this process (known as cavitation), millions of shock waves are created and a high level of energy is released [75], leading to dispersion of nanomaterials in the liquid. A short duration of ultrasonic treatment $(15$ minutes at $20 \mathrm{kHz}$ frequency and amplitude setting of 50\%) using a titanium probe was found successful to prepare homogeneous aqueous dispersion of VCNFs (1.14 wt.\%) [78]. However, this technique could not ensure homogeneous distribution of CNTs within cement, meaning that a homogeneous nanomaterial dispersion in water does not guarantee a good dispersion in the nanocomposites as well. This fact necessitates the use of various chemical routes in combination with ultrasonication to improve the dispersion stability, thus preserving the nanomaterial dispersion up to the composite stage.

\subsection{Chemical Methods}

5.2.1. Use of Surfactant. Surfactants can improve aqueous dispersion of nanomaterials by reducing surface tension of water and, moreover, lead to stable dispersion as a result of electrostatic and/or steric repulsions between the surfactant molecules adsorbed on the nanomaterials surface. However, the dispersion capability of surfactants strongly depends on their concentration, and an optimum surfactant to nanomaterials ratio should be used for preparing cementitious composites. Among the various concentrations studied, it was observed that surfactant/CNT ratios of 4.0 and 6.25 (by weight) were efficient in preparing homogeneous aqueous dispersion of $0.16 \mathrm{wt}$ \% MWCNT using ultrasonication process (operated at $500 \mathrm{~W}$, amplitude of 50\%, energy of 1900$2100 \mathrm{~J} / \mathrm{min}$ and at cycles of $20 \mathrm{~s}$ ) [81]. Moreover, the dispersion homogeneity was preserved in the nanocomposites due to the better dispersion stability, and only individual nanotubes were observed in the fracture surface (Figure 5). Lower surfactant/CNT ratios (0 and 1.5), however, could not disperse CNTs well, leading to presence of large CNT clusters within the composites. Similarly, VCNFs (0.048 wt. of cement) could also be dispersed homogeneously (Figure 6) using a surfactant/CNF ratio of 4.0 [82].

Besides concentration, it has been observed that the type and structure of surfactant also have significant influence on the dispersion of carbon nanomaterials in water and subsequently within cementitious composites. Among the various surfactants such as Sodium dodecylbenzenesulfonate (SDBS), sodium deoxycholate (NaDC), Triton X-100 (TX10), Gum Arabic (GA), and cetyl trimethyl ammonium bromide (CTAB), the anionic one (SDBS) provided the best aqueous dispersion of MWCNTs (prepared using surfactant concentration of $2 \mathrm{wt} . \%$ and magnetic stirring for $10 \mathrm{~min}$ at $300 \mathrm{rpm}$ combined with ultrasonication using a tip sonicator at $40 \mathrm{~W}$ for 90 rounds, each of $90 \mathrm{~s}$ and $10 \mathrm{~s}$ rest in between), which was stable after 70 minutes of ultracentrifugation and 60 days of sitting [83]. The result was even better when SDBS was used in combination with Triton X-100 (nonionic) in the weight ratio of $3: 1$. The better stabilization in case of SDBS was attributed to the benzene ring in the hydrophobic chain, smaller charged $\mathrm{SO}_{3}{ }^{2-}$ head group, and relatively longer alkyl hydrophobic chain [84]. The dispersion ability of various surfactants was found in the following order: SDBS and TX10 $>\mathrm{SDBS}>\mathrm{NaDC}$ and $\mathrm{TX} 10>\mathrm{NaDC}>\mathrm{AG}>\mathrm{TX} 10>\mathrm{CTAB}$. The cationic surfactant $\mathrm{CTAB}$ showed the lowest dispersion capability because of the absence of benzene ring on the long chain and the positive charge which might have neutralized the negative charge of MWCNTs in aqueous solution. The fracture surface of cement nanocomposite containing $0.2 \mathrm{wt} . \%$ MWCNTs dispersed using SDBS/TX10 combination showed a very uniform distribution of CNTs. Sodium dodecyl sulfate (SDS) has also been reported as an effective anionic surfactant for fabricating CNT/cement nanocomposites [85]. However, one drawback of using surfactants as nanomaterial dispersant is the lack of connectivity of nanomaterials within cementitious matrix due to blocking by surfactant molecules, and this fact affects the electrical and piezoresistive properties of nanocomposites [85]. 

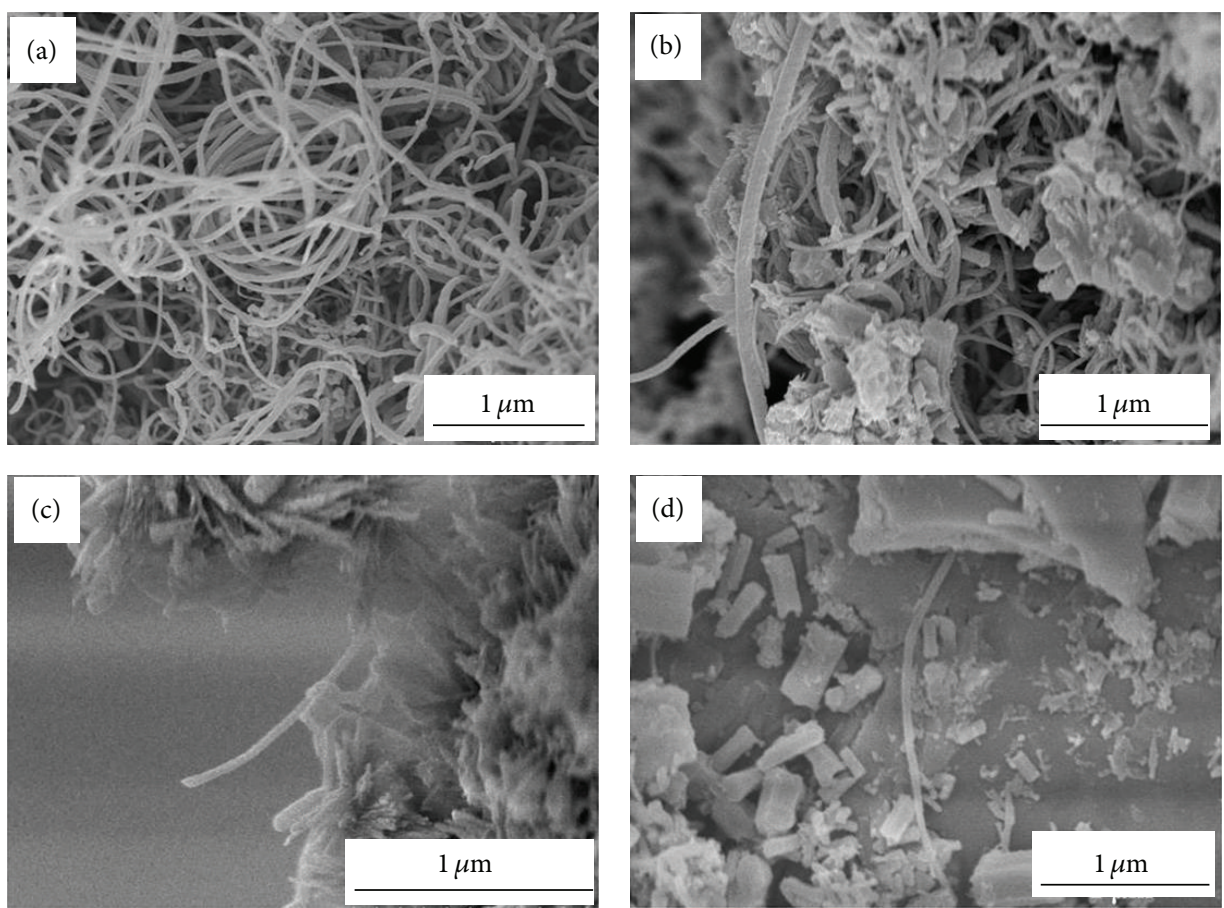

Figure 5: Dispersion of MWCNT within cementitious composites prepared using different surfactant to MWCNT weight ratio: (a) 0, (b) 1.5, (c) 4.0 , and (d) 6.25 [81].
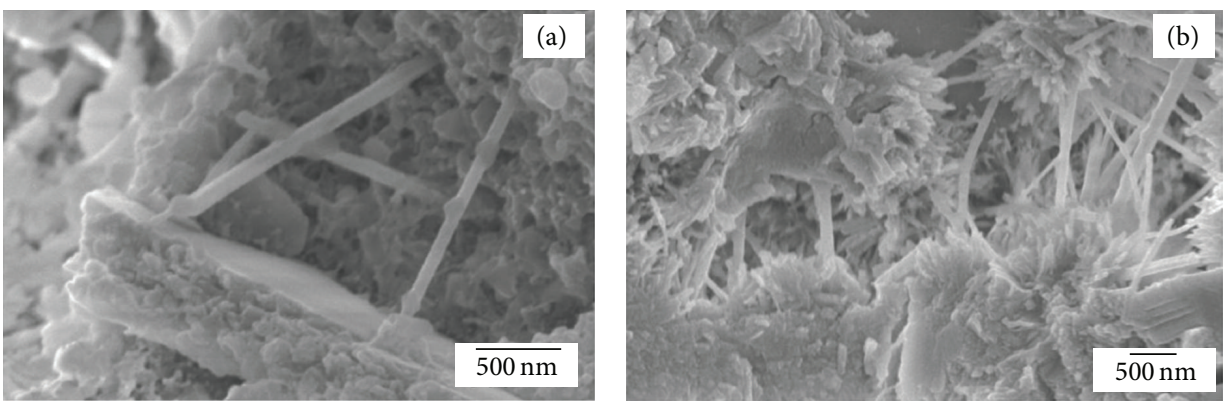

FIGURE 6: Fracture surface of CNF/cement nanocomposites, showing individually dispersed CNFs [82].

Surface decoration of carbon nanomaterials using polymeric surfactants has been reported to introduce steric repulsion between the nanomaterials, leading to their homogeneous dispersion. The surface of MWCNTs could be covered with acrylic acid polymer through ultrasonication in water, as can be seen from Figure 7 [86], and this led to very good aqueous dispersion of CNT (Figure 8). Methylcellulose is another polymer which has been used to prepare highly stable aqueous dispersion of CNT for fabricating cementitious nanocomposites [87-89].

5.2.2. Use of Cement Admixtures. Polycarboxylate, which is commonly used as a superplasticizer within cement paste, was also found to be an effective dispersant of CNT [90]. Among the various cement admixtures such as alkylbenzene sulfonic acid (air entraining agent), styrene butadiene rubber copolymer latex, aliphatic propylene glycol ether including ethoxylated alkyl phenol, polycarboxylate, calcium naphthalene sulfonate, naphthalene sulphonic acid derivatives, and lignosulfonate, very stable dispersions stable up to 9 days were obtained with the air entrainer, polycarboxylate, and lignosulfonate in the sedimentation test. However, the use of high concentration of lignosulfonate required for good CNT dispersion is not recommended to avoid delay in the setting time of Portland cement [91]. Also, despite of a good aqueous dispersion, the use of alkylbenzene sulfonic acid could not lead to a homogeneous CNT dispersion in the hardened cement paste. On the contrary, the use of polycarboxylate resulted in a very good dispersion of MWCNT in water as well as in the hardened cement paste and, therefore, proved to be the best dispersant among the various admixtures used in cement.

Silica fume, an amorphous polymorph of silicon dioxide, is also used as a pozzolanic material in concrete production [92-94]. Silica fume consists of spherical particles with average diameter of $150 \mathrm{~nm}$ and has been found to improve microfiber dispersion within cement $[95,96]$. The influence of silica fume on carbon nanomaterial dispersion has also 


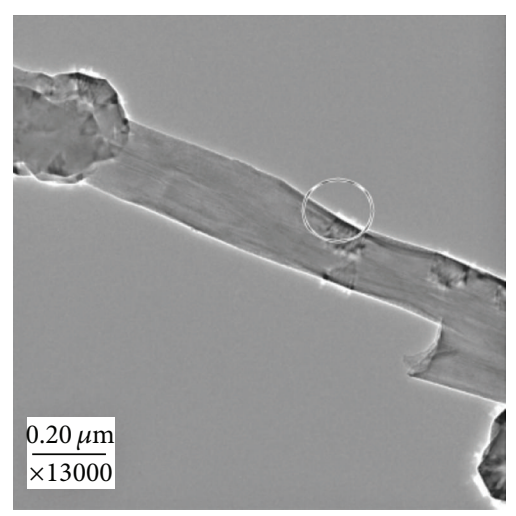

(a)

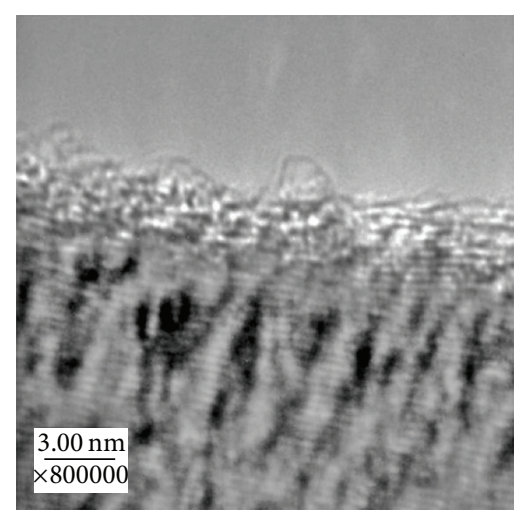

(b)

FIGURE 7: TEM image of MWCNTs showing presence of acrylic acid polymer on the surface at magnifications of 13000x (a) and 800000x (b) $[86]$.

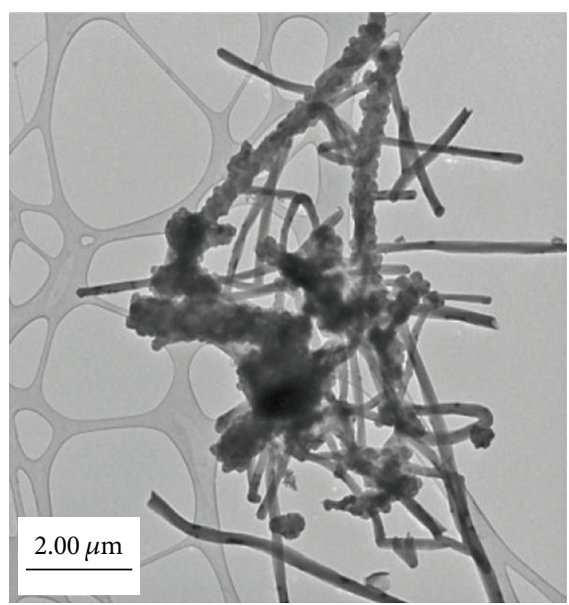

(a)

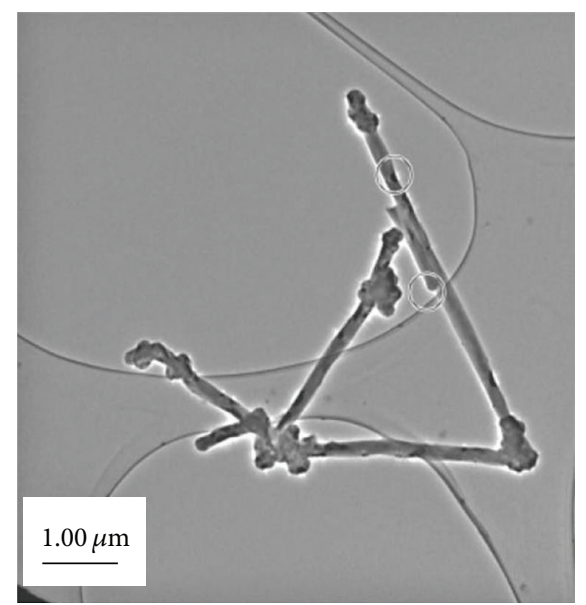

(b)

FIGURE 8: TEM image of MWCNT dispersion in water without any treatment (a) and with acrylic acid polymer and sonication (b) [86].

been studied [97]. It was observed that the cement nanocomposites prepared through dry mixing of $2 \mathrm{wt} . \%$ CNFs with cement and silica fume (10 wt.\%) using a conventional threespeed mixer (followed by water addition) showed both CNF agglomerates as well as individually dispersed nanofibers. However, in absence of silica fume only CNF agglomerates were observed, indicating positive influence of silica fume [98]. The better dispersion in the presence of silica fume was attributed to the smaller size (100 times smaller as compared to anhydrous cement particles) of silica fume particles which could disrupt the Van der Waals forces between individual CNFs, thereby mechanically separating some of them during the dry mixing process and reducing the CNF clumps. Additionally, the silica fume particles present within the CNF clumps as well as individual CNFs could also act as the silicon source for the formation of $\mathrm{Ca}-\mathrm{Si}$-rich phases and nucleation sites for the self-assembly of $\mathrm{Ca}$-Si-rich phases.

5.2.3. Covalent Functionalization. The most common approach to improve the dispersion ability of CNTs/CNFs in water or polymeric matrices is the covalent functionalization.
Frequently, carbon nanomaterials have been treated with strong acids such as nitric acid or a mixture of sulfuric and nitric acid $(3: 1)$ to oxidize the surface and create functional groups such as carboxylic. Covalent functionalization using acid mixture has been found successful to disperse CNTs individually within cementitious matrix [99]. Moreover, CNTs became tightly wrapped by the C-S-H phase of cement, due to covalent bonding between $\mathrm{COOH}$ or $\mathrm{C}-\mathrm{OH}$ groups of nanotubes and C-S-H. Similar observations were also made in case of surface-functionalized CNFs using $70 \%$ nitric acid [100]. However, although surface-treated CNTs could be homogeneously dispersed within cementitious matrix, the dispersed CNTs could not form a well-connected threedimensional network (as evident from Figure 9) required for good electrical conductivity or piezoresistive properties due to fewer contact points and covering of surface by C-S-H phases [101].

Functionalization of CNTs with strong acids forms carboxylated carbonaceous fragments (CCFs), which are organic molecules consisting of condensed aromatic rings with several functional groups [102]. Although CCFs have 


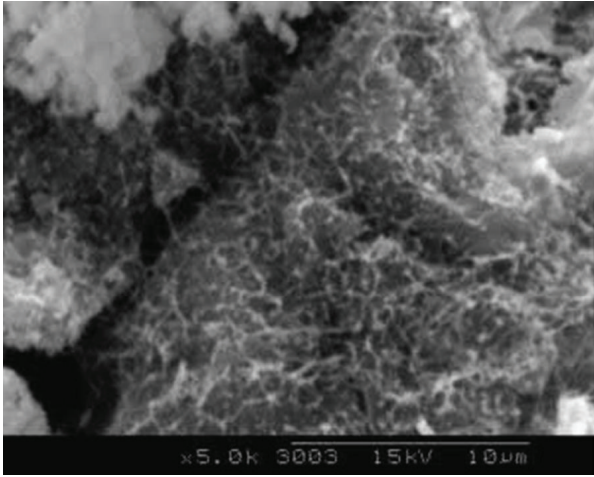

(a)

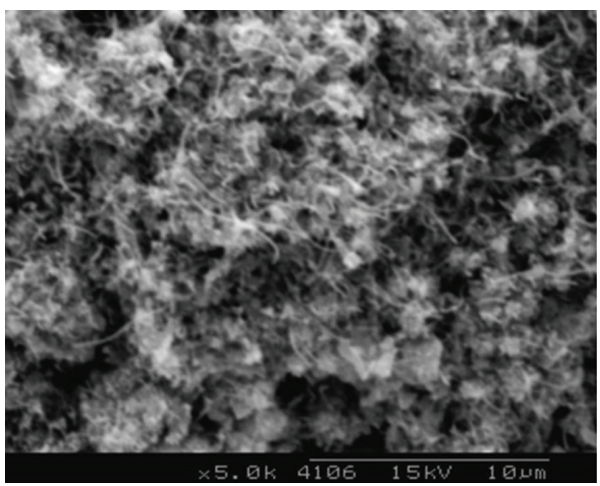

(c)

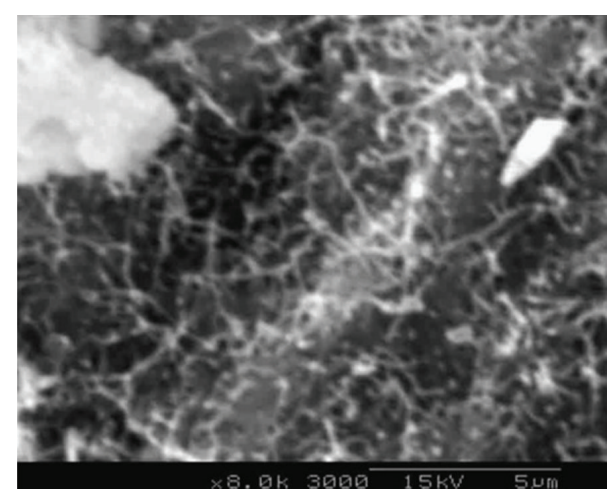

(b)

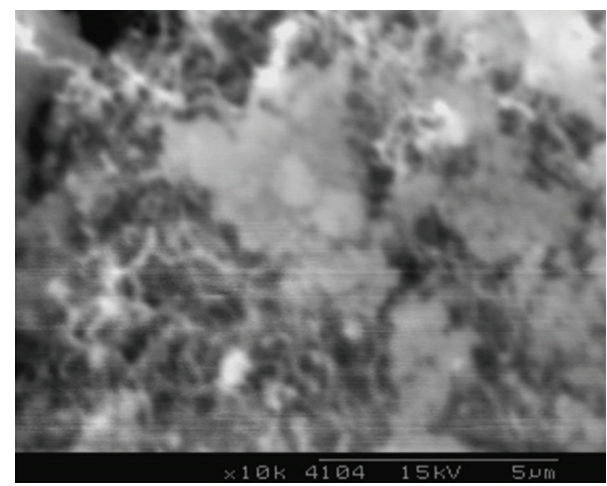

(d)

FIGURE 9: SEM image of cement nanocomposites with untreated CNTs ((a), (b)) and acid-treated CNTs ((c), (d)) [101].

functional groups which can react with cement, they do not contribute to the mechanical properties as they are only small fragments and do not have proper structure to carry mechanical loads. CCFs can be removed through washing of functionalized CNTs using acetone. CNTs, either containing CCFs or free from CCFs, resulted in floccules formation when $\mathrm{Ca}(\mathrm{OH})_{2}$ was added to the dispersion, indicating reaction between the surface functional groups of $\mathrm{CNT}$ and $\mathrm{Ca}^{2+}$ ions. The hydration of cement on the surface of functionalized CNTs was also observed, as shown in Figure 10.

5.2.4. Combination of Various Chemical Methods. The combination of surface functionalization with polymers has been found to provide more stable aqueous dispersion of CNT than using only polymers or functionalized CNTs [86]. The dispersions of nonfunctionalized MWCNTs using acrylic acid polymer or gum arabic were found stable only up to 2 hours after which sedimentation was observed. Similarly, aqueous dispersion of functionalized nanotubes also showed poor long-term stability. On the contrary, functionalized MWCNT dispersion prepared using acrylic acid polymer showed stability more than 2 months. The long polyacrylic acid polymers were adsorbed on the surface of functionalized nanotubes and increased the steric barrier towards their agglomeration. In a similar way, use of surfactant (sodium dodecylbenzene sulfonate) to homogeneously disperse carboxyl-functionalized MWCNTs within cementitious matrix was found to be very effective [103].

5.3. Novel Routes of CNT Dispersion. In order to avoid the problematic and time-consuming process of dispersing CNTs within cementitious matrix, an innovative method of fabricating cementitious nanocomposites through growth of CNTs onto the cement particles has been recently reported [104]. CNTs were grown in a chemical vapour deposition (CVD) reactor at $400-700^{\circ} \mathrm{C}$ using acetylene as the main carbon source and carbon monoxide and dioxide as the additives to enhance the yield. Cement powder was feed in the reactor continuously at a speed of $30 \mathrm{~g} / \mathrm{h}$, and the oxides $\left(\mathrm{Fe}_{2} \mathrm{O}_{3}\right)$ present in the cement acted as catalysts for CNT growth, without the need for an additional catalyst support used in the conventional CVD process. The concept of preparing cement nanocomposites using this route has been illustrated in Figure 11. The TEM images of CNT-grown cement particles showed complete coverage of cement particles by carbon nanomaterials and formation of MWCNTs as well as CNFs, as shown in Figure 12. More recently, CNTs were also grown on the silica fume particles, impregnated with iron salt, using acetylene as the carbon source [105]. CNTs with 5-10 walls and diameters of $10-15 \mathrm{~nm}$ were grown at $600^{\circ} \mathrm{C}$ and with $12-$ $20 \mathrm{~nm}$ diameters were produced at $750^{\circ} \mathrm{C}$ (Figure 13). Silica 


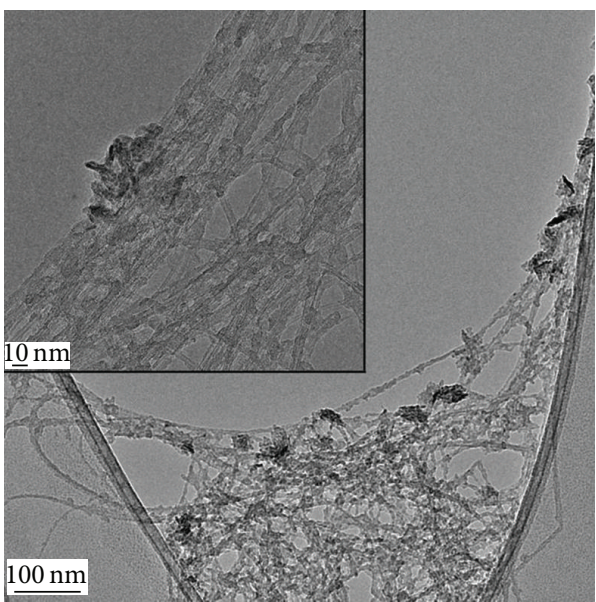

(a)

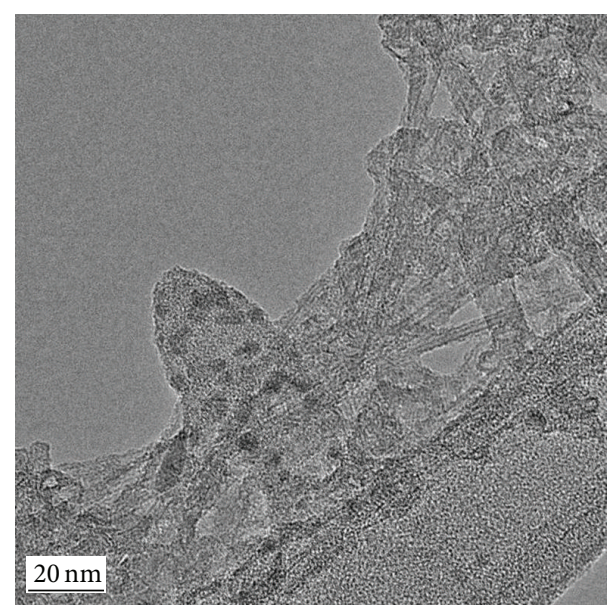

(b)

FIGURE 10: TEM image of CCF-free FWCNTs after hydration for 1 hour (a) and 5.5 hour (b) [102].

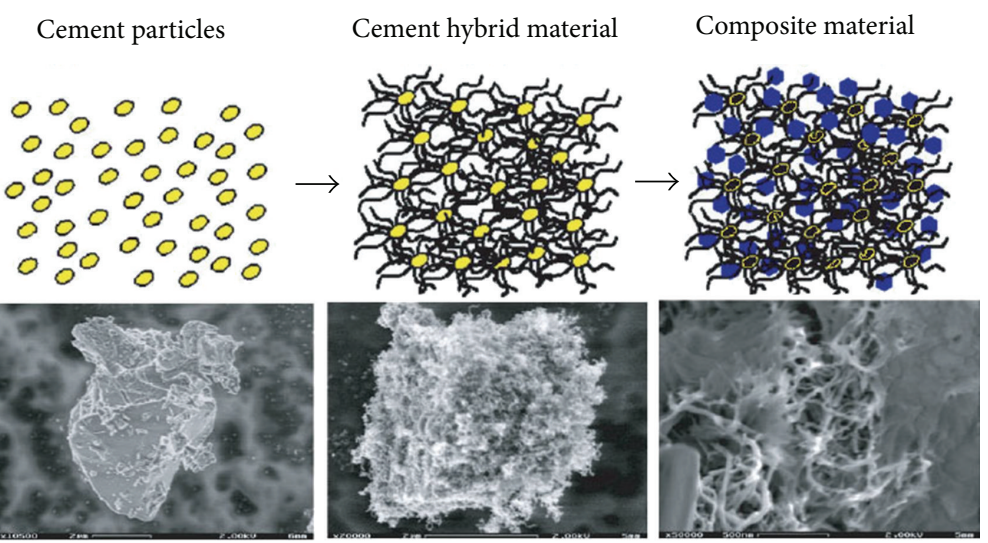

FIGURE 11: Schematic diagram showing concept of incorporating CNTs/CNFs within cementitious composites by their direct growth on cement particles [104].
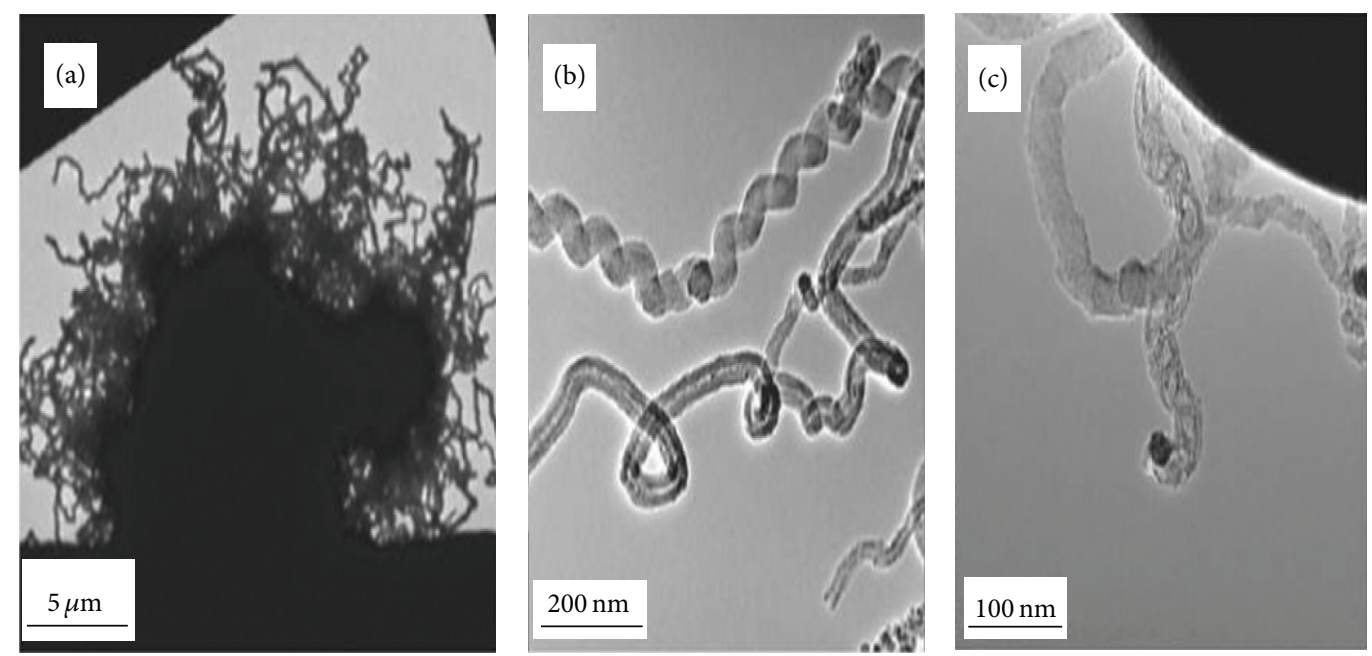

FIGURE 12: TEM image showing complete coverage of cement particles by carbon nanomaterial (a), formation of MWCNT (b), and CNF formation (c) [104]. 


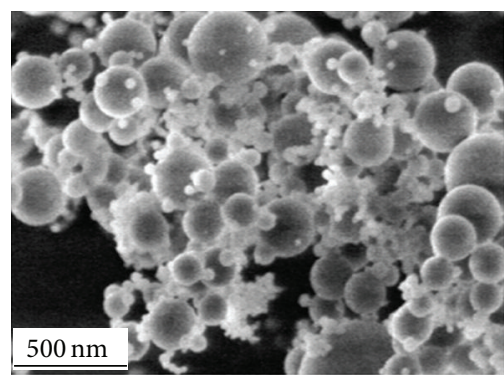

(a)

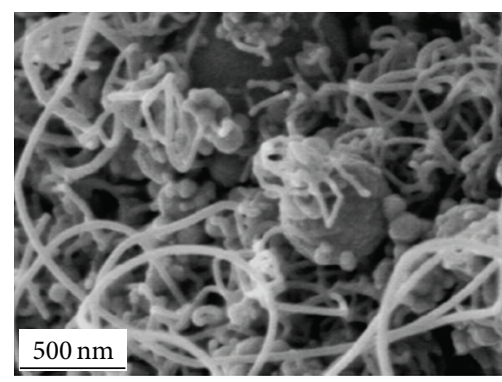

(b)

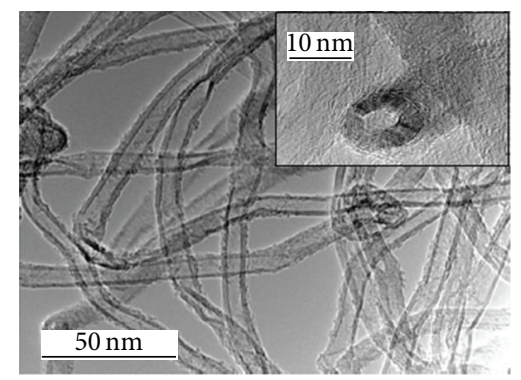

(c)

FIgURE 13: SEM images of pristine silica particles (a), growth of CNTs on silica particles at $600^{\circ} \mathrm{C}(\mathrm{b})$, and TEM image of CNTs grown on silica particles at $600^{\circ} \mathrm{C}$ (c) [105].

fume, which is used as an admixture, can therefore be utilized to introduce CNTs within cementitious matrices.

5.4. Large-Scale Production of CNT Dispersion. A technique for producing highly concentrated MWCNT/water suspensions that can be used for developing cement nanocomposites at large scale has been recently developed [106]. In this process, MWCNTs were homogeneously dispersed in water using surfactant (MWCNT to surfactant weight ratio of 4.0) using a tip sonicator. When this CNT dispersion was centrifuged at $28,000 \mathrm{rpm}$ using a swing bucket rotor, the dispersed MWCNTs started precipitating at the bottom of the tube, and complete sedimentation was achieved after 11 hours. The supernatant solution was then decanted down to keep only $20 \%$ of the initial volume of the solution, and CNTs were redispersed in this solution through ultrasonication for 40 minutes. The concentration of MWCNTs increased 5 times using this process, as revealed by optical absorbance spectroscopy. The concentrated MWCNT solution, when diluted by adding the same amount of water previously decanted, showed same concentration as the reference nonconcentrated MWCNT suspension. Moreover, it was quite interesting to note that the cementitious nanocomposites prepared using the concentrated MWCNT suspension (after dilution) exhibited similar mechanical properties as those obtained using the reference non-concentrated MWCNT suspensions, indicating that the dispersion of MWCNTs was preserved even after the concentration process through centrifugation. Therefore, this process can be utilized to prepare large-scale production of CNT admixtures for developing cementitious nanocomposites.

\section{Microstructure of Carbon Nanomaterial/Cement Nanocomposites}

It has been reported by several researchers that carbon nanomaterials can significantly change the microstructure of cement, and this is one of the principal reasons for improvement in mechanical properties. Significant difference between the porosity of Portland cement and cement/CNT nanocomposites was observed [107]. The total porosity and surface area both decreased with CNT addition. This was attributed to the fact that CNTs filled in the pores, mainly the mesopores (size less than $50 \mathrm{~nm}$ ), between the hydration products, and, thereby, produced a denser microstructure than the unreinforced cement. Moreover, this also resulted in very good interaction between the hydration products and dispersed CNTs, which were seen densely inserted between the $\mathrm{C}-\mathrm{S}-\mathrm{H}$ and $\mathrm{CH}$ phases of cement (Figure 14). Similar findings were also made in case of cement containing $0.5 \mathrm{wt} . \%$ surface-treated MWCNTs [100], which resulted in 64\% lower porosity and $82 \%$ lower pores with size more than $50 \mathrm{~nm}$. On the contrary, cement composites containing microscale fibres such as carbon showed much higher porosity than the Portland cement samples. Nanoindentation tests also showed lower probability of porous phase in a cement nanocomposite containing 0.08 wt.\% MWCNT than Portland cement, indicating lower porosity in case of nanocomposites [81].

\section{Mechanical Properties of CNT/CNF Reinforced Cementitious Composites}

Early investigations showed that CNTs have strong influence on the hydration process and hardness of cementitious composites [108]. In spite of inhomogeneous CNT dispersion in nanocomposites with cement/CNT ratio of 0.02 (by weight), Vickers hardness improved up to $600 \%$ in case of 0.4 and 0.5 water/cement ratios in the early hydration stages, although no improvement in hardness was observed after 14 days of hydration. These early results reflected the potential of CNT for improving mechanical properties of cement. However, as in case of polymer, the reinforcing efficiency of CNT/CNF in cementitious matrices and the resulting mechanical properties of nanocomposites also depend on several critical factors, as discussed in the following sections.

7.1. Influence of Dispersion. Dispersion of nanomaterials has been identified as one of the principal factors which influence the mechanical properties most. Therefore, the parameters which control the dispersion behaviour have strong influence on the mechanical properties also. For example, the type and structure of surfactant were found to be very important with respect to the mechanical properties. Among the various surfactants such as SDBS, NaDC, TX10, AG, and CTAB, the highest flexural and compressive properties were achieved 

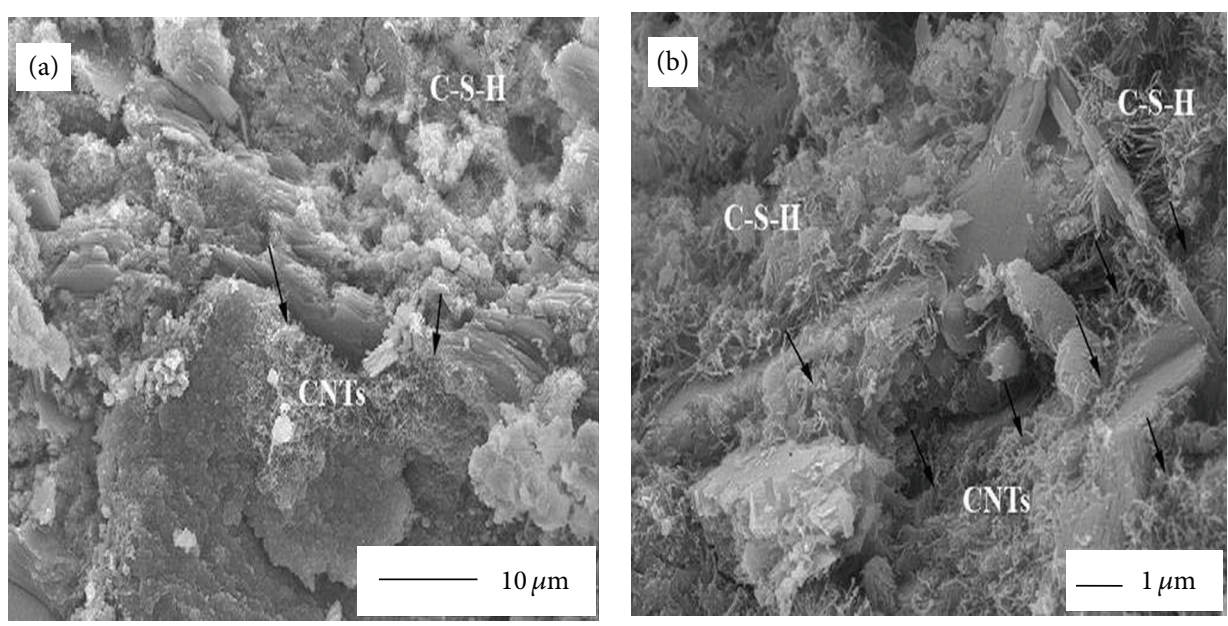

FIGURE 14: SEM micrographs of $1 \mathrm{wt}$ \% CNT/cement paste at 28 days of hydration at different magnifications [107].

with $\mathrm{NaDC}$, whereas the lowest variation as well as secondbest flexural and compressive strengths were obtained in case of 3:1 mixture of SDBS and TX10. The improvements in case of $\mathrm{NaDC}$ were $35.45 \%$ and $29.5 \%$ as compared to plain cement paste. The highest improvement in case of $\mathrm{NaDC}$ was due to good dispersion of MWCNTs as well as formation of strong interface between cement matrix and MWCNTs. Similarly, better mechanical properties in case of SDBS and TX10 mixture resulted from the best dispersion ability of this combination and also good bonding between MWCNTs and matrix. Microscopy study in case of this surfactant combination suggested that MWCNTs were well distributed within the cement matrix as a net-like structure and acted as bridges between the microcracks, resulting in superior mechanical performance [83]. Similarly, among the various cement admixtures, improved dispersion of CNT in water as well as within cement was observed only in case of polycarboxylate, and, therefore, the cement paste containing $0.8 \%$ polycarboxylate and $0.5 \%$ CNT showed very good flow behaviour even with low water ratio (0.35) and presented a compressive strength $25 \%$ higher than the control cement samples [90]. The length and concentration of CNTs also influence their dispersion behaviour and, therefore, are controlling factors for mechanical properties of nanocomposites [81]. It was noticed that short MWCNTs $(10-30 \mu \mathrm{m})$ provided better dispersion and flexural properties even when used at higher concentrations (0.08 wt.\%), whereas long MWCNTs $(10-100 \mu \mathrm{m})$ should be used at lower concentrations $(0.048 \mathrm{wt} . \%)$ to maintain better dispersion and to achieve good flexural properties. It was also observed that short CNTs at higher concentrations were better in terms of mechanical properties due to relatively better dispersion, reduced CNTfree volume of cement paste, and better filling of nanosized voids [109]. However, reduction of CNF's aspect ratio due to either debulking process or ultrasonication was found detrimental to mechanical properties, and it was observed that a higher ultrasonication energy than optimum led to reduction in nanomaterials' aspect ratio and deterioration of mechanical properties [110].
Homogeneous dispersion of CNTs/CNFs achieved through their growth onto cement particles was reported to provide 2 times higher compressive strength than the pristine cement composites after 28 days of hydration [104]. This dispersion process led to well distribution of CNTs and CNFs embedded into the hydration products of $\mathrm{C}-\mathrm{S}-\mathrm{H}$ phases and, therefore, bridged the adjacent cement particles (Figure 15), resulting in strong improvements in compressive strength. Although a homogeneous dispersion of carbon nanomaterials is extremely necessary for enhancing mechanical performance of cementitious composites, it has been observed that even when they are poorly dispersed, they can prevent the formation of shrinkage cracks and significantly improve the mechanical performance, especially when cuing is done in absence of moisture for the first 24 hours [111].

\subsection{Influence of Nanomaterial Surface Treatment and Inter-} face. The interface between nanomaterials and cementitious matrix controls the load transfer between them and, therefore, significantly influences the mechanical properties of composites. Formation of covalent bonding between $\mathrm{COOH}$ or $\mathrm{C}-\mathrm{OH}$ groups of functionalized CNTs and C-S-H phases of cement matrix has been observed through FTIR studies [99] and was also supported by microscopy studies which showed tight wrapping of functionalized CNTs by C-S-H phases. Cement nanocomposites containing surface-treated MWCNTs presented much better flexural and compressive properties as compared to plain cement paste. Flexural and compressive strength improved up to $25 \%$ and $19 \%$, respectively, using $0.5 \mathrm{wt} . \%$ functionalized CNT. It has been observed that ensuring a good dispersion through acrylic acid polymer wrapping does not ensure improved mechanical properties of composites, due to improper load transfer at the interface [86], whereas $0.045 \%$ of functionalized MWCNTs showed nearly $50 \%$ increase in compressive strength when dispersed using the same process, indicating strong influence of the interface. Improvement of mechanical 


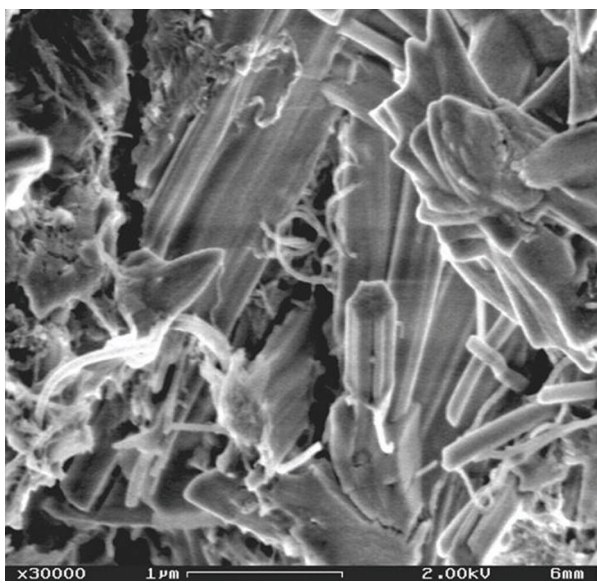

(a)

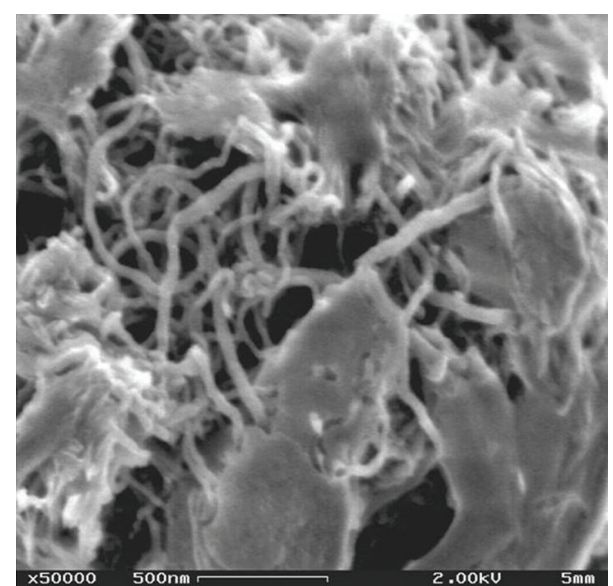

(b)

FIGURE 15: SEM image of hardened cement paste (28 days) after mechanical test at different magnifications [104].

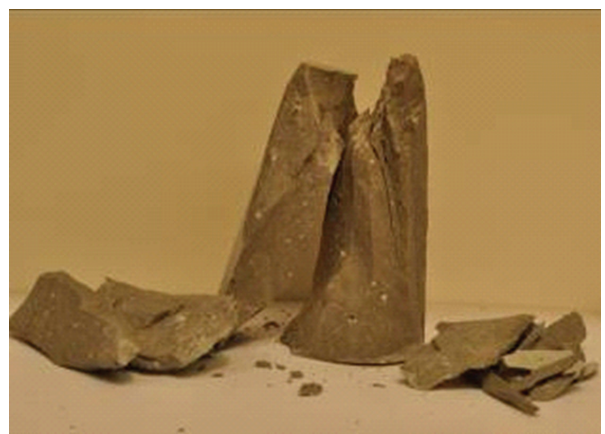

(a)

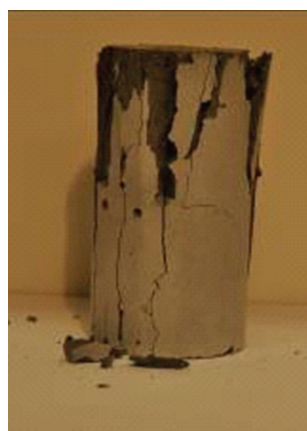

(b)

FIGURE 16: Post-compression testing structural integrity of plain cement paste (a) and cement paste containing 0.5 wt. $\%$ surface-treated CNFs (b) $[100]$

properties using functionalized nanomaterials can be further enhanced through removal of CCFs (see Section 5.2.3) from the nanomaterials surface [102]. It has been reported that the incorporation of functionalized CNTs ( $0.01 \mathrm{wt} . \%)$ containing CCFs resulted in only $13 \%$ improvement in compressive strength, whereas after removal of CCFs using acetone resulted in very strong improvement in compressive strength, up to $97 \%$ using only $0.03 \mathrm{wt} . \% \mathrm{CNT}$. This was attributed to the fact that functionalized CNTs became less accessible for the reaction with cement hydration products and their nucleation, due to presence of these CCFs. Similarly the presence of surfactant molecules on the nanomaterial surface was also found detrimental to the mechanical properties, due to blocking of direct contacts between surface functional groups and cement hydration products, and a reduction of $65 \%$ in compressive strength was observed using $4 \%$ SDS.

Use of surface-treated CNTs/CNFs also improves the posttesting mechanical integrity of cement nanocomposites [100]. Cement samples containing $0.5 \mathrm{wt} \%$ surface-treated CNFs were found to maintain better structural integrity than the control samples after compression testing, as shown in Figure 16. Better structural integrity in case of $\mathrm{CNF} /$ cement composites resulted due to the restriction in crack propagation by the entangled clumps of CNF inside cement cavities, leading to bridging of cracks, and also due to individually dispersed CNFs within the cement matrix. It was also observed that, after decalcification using ammonium nitrate solution for 95 days, the samples containing CNFs showed better ductile behaviour with slow load dissipation after failure, as presented in Figure 17. This indicates better durability of $\mathrm{CNF} /$ cement nanocomposites as compared to the plain cement paste.

In spite of several benefits of using functionalized nanomaterials, surface functionalization method should be used carefully in case of cementitious matrices. There is a possibility that functionalized CNTs can absorb water present in the cement paste due to their hydrophilic nature and may adversely affect the cement hydration. It has been noticed that the cement nanocomposites containing $0.5 \mathrm{wt} \%$ carboxylfunctionalized MWCNTs led to formation of lower amount of tobermorite gel due to improper hydration process and significantly deteriorated the mechanical properties [112].

Besides surface functionalization, the interface in a carbon nanomaterial/cement composite also depends on the 


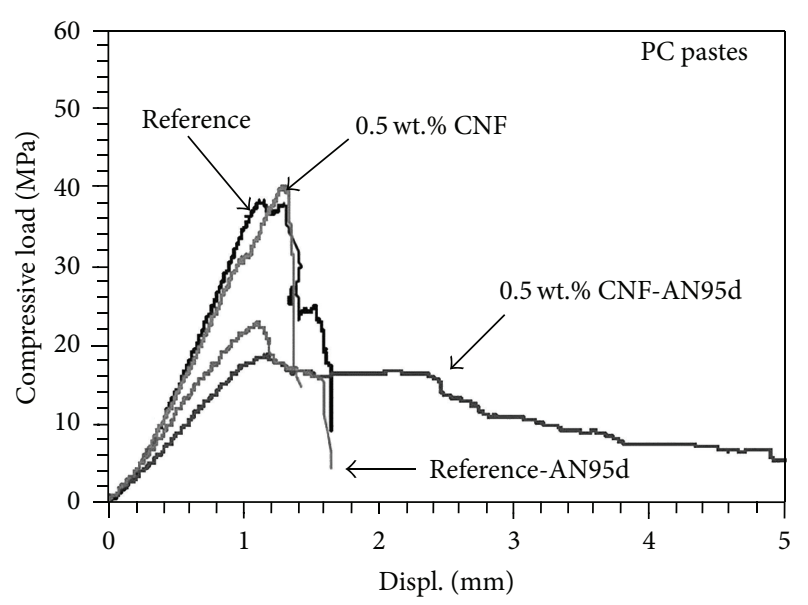

FIGURE 17: Comparison of compressive behaviour of cement paste and $\mathrm{CNF} /$ cement composites before and after decalcification [100].

surface feature of nanomaterials. The CNF variety with rougher surface containing conically shaped graphitic planes was found to be very effective in enhancing mechanical properties as compared to the CNFs having smoother surface containing CVD layers [110].

7.3. Influence of Microstructure. The improvement of mechanical properties achieved in case of well-dispersed MWCNT/cement nanocomposites has been found to be much higher than that predicted using theoretical equations [81]. There may be several possible reasons for this fact. The decrease in cement porosity and improvement of its microstructure is certainly one of them. The increase in the amount of high stiffness C-S-H phases in presence of CNT, as revealed from the nanoindentation tests, is another reason for such strong improvement in mechanical properties. Improvement of microstructure is also the primary cause for mechanical property enhancements in case of non-autoclave foam concrete. It was found that the use of CNTs $(0.05 \%$ by mass) as the reinforcement of foam concrete stabilized its structure by decreasing the pore wall percolation and ensuring better pore size uniformity (Figure 18) [113]. This resulted in strong improvement in the compressive strength (70\%) associated with a decrease in the average density of concrete from $330 \mathrm{~kg} / \mathrm{m}^{3}$ to $309 \mathrm{~kg} / \mathrm{m}^{3}$. Improvement of microstructure and resulting enhancements in mechanical properties due to CNT addition has also been noticed in case of fly ash cement [114-119]. Fly ash cement samples containing CNTs presented higher density than control fly ash and PC samples, due to filling of cement pores by CNTs, and a denser microstructure [120]. The compressive strength of fly ash cement composites containing $1 \mathrm{wt} . \%$ CNT reached that of PC at 28 days and 60 days, which is usually higher than the compressive strength of fly ash cement due to its slow hydration rate.

7.4. Mechanical Properties of Hybrid Cement Nanocomposites. Hybrid cement nanocomposites are analogous to the multiscale polymer nanocomposites containing reinforcements of different scales such as micro and nano. Hybrid cement nanocomposites containing both CNTs and nano metakaolin (NMK) have been reported [121]. NMK is a silica-based material, which can react with $\mathrm{Ca}(\mathrm{OH})_{2}$ to produce C-S$\mathrm{H}$ gel at room temperature, and incorporation of $\mathrm{NMK}$ into concrete was found to significantly improve the early strength, increase resistance to alkali-silica reaction and sulfate, and can increase toughness and durability [122-125]. Additionally, homogeneous dispersion of exfoliated NMK was found to significantly improve the compressive strength of cement (18\% using 6 wt.\% NMK) due to reduction of porosity and improvement in the solid volume and bond strength of cement through pozzolanic reaction between silicon and alumina elements present in NMK and the elements of calcium oxide and hydroxide in cement. Also, the presence of NMK could probably disrupt the attractive forces between CNTs during dry-mixing process and could separate them leading to their individual dispersion. Additionally, the presence of NMK particles mixed with the dispersed CNTs could act as $\mathrm{Si}$ source for the formation of $\mathrm{Ca}$-Si-rich phases, and CNTs could further act as the nucleation sites for the selfassembly of Ca-Si phases. Due to these reasons, addition of up to $0.02 \%$ CNT resulted in $11 \%$ higher compressive strength as compared to the mortar containing only NMK.

Hybrid cement nanocomposites containing polyvinyl alcohol (PVA) micro-fibres and CNFs were also developed and reported to have higher Young's modulus, flexural strength, and toughness than plain cement, cement containing only PVA micro-fibres, or CNFs [82]. It was observed that cement containing CNFs presented much higher load carrying capability at the same CMOD (crack mouth opening displacement) during the early stages of loading (Figure 19). Using only $0.048 \%$ CNFs, Young's modulus, flexural strength, and toughness improved up to $75 \%, 40 \%$, and $35 \%$, respectively. On the contrary, use of PVA micro-fibres improved the Young's modulus and flexural strength only marginally, but the fracture toughness increased tremendously, retaining the load for ten times higher CMOD than plain cement. Therefore, in the hybrid composites, the pre-peak behaviour was mainly controlled by CNFs, whereas the post-peak behaviour was influenced by mainly PVA micro-fibres. The fracture surface study suggested good bonding between cement and both CNFs and PVA microfibers and bridging of micropores by PVA fibres and pores at nanolevel by CNFs. The hybrid cementitious composites showed up to $50 \%$ improvement in flexural strength, 84\% improvement in Young's modulus, and 33 times (3351\%) improvement in fracture toughness over plain cement matrix. Similarly, hybrid cement nanocomposite bar containing 2.25\% short carbon fibres and $0.5 \%$ MWCNT was found to have much higher tensile modulus (60\%), load carrying capacity (54\%), and failure strain (44\%) as compared to plain cement bars [126].

A list of important literature on the dispersion techniques as well as improvement of microstructure and mechanical properties of cementitious composites using carbon nanomaterials is provided in Table 1 . However, besides mechanical properties, degradation behaviour of cement is another important characteristic that influences the durability of 


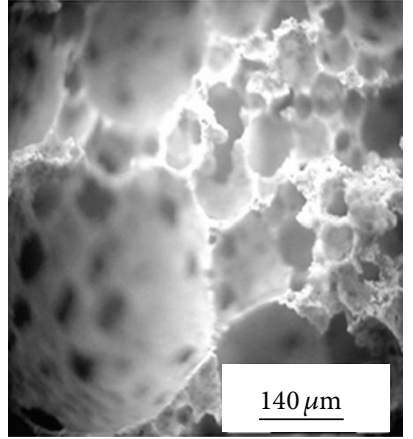

(a)

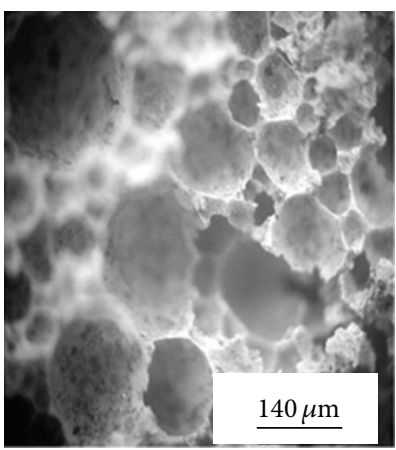

(b)

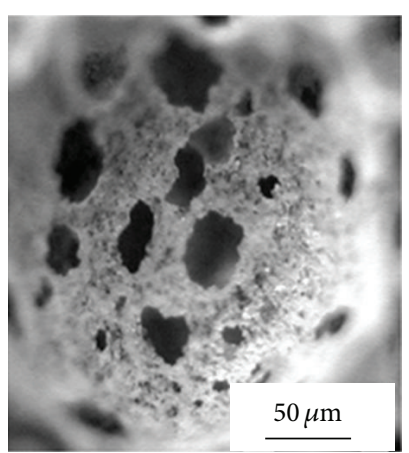

(c)

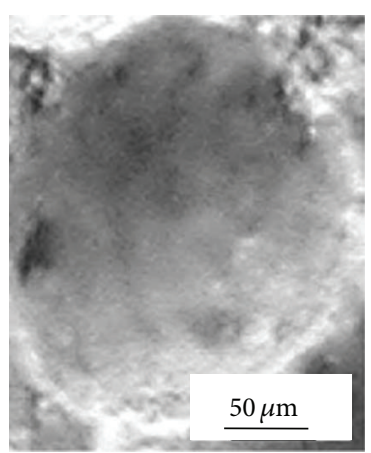

(d)

FIGURE 18: Structure of cement-foam concrete: (a) without nanotubes, (b) with 0.05\% CNT (pore walls), (c) without CNT (perforated), and (d) stabilized with addition of $0.05 \%$ CNT [113].

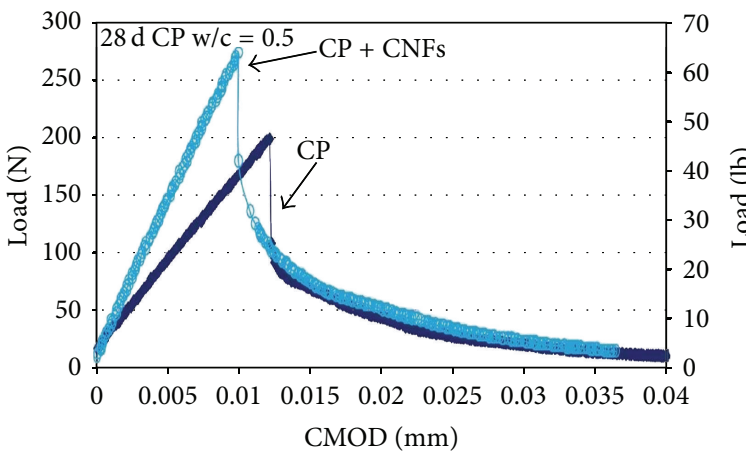

(a)

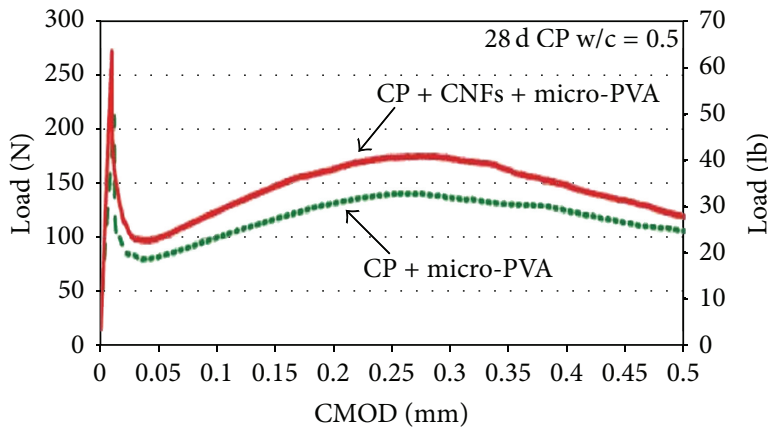

(c)

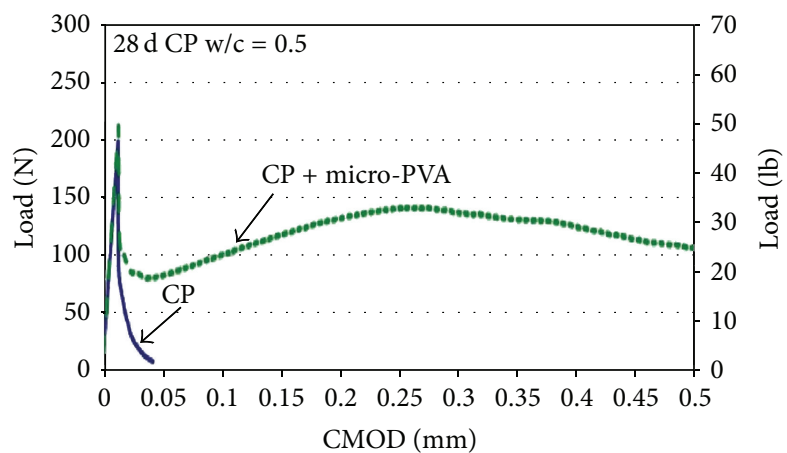

(b)

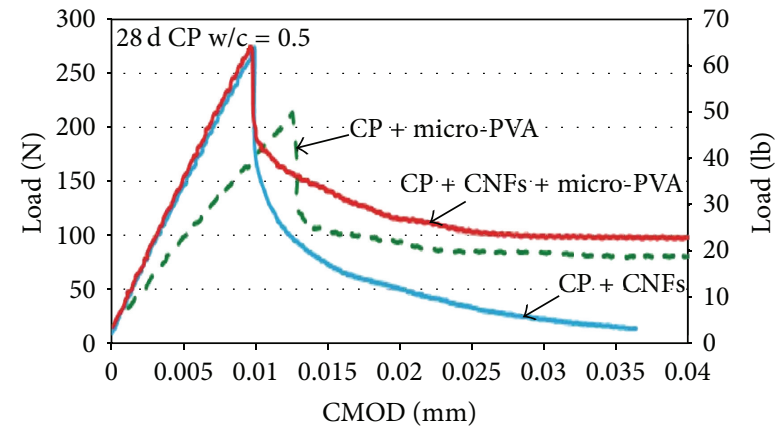

(d)

FIGURE 19: Load-CMOD curves for (a) plain cement paste and cement paste containing CNFs, (b) cement paste and cement paste containing PVA microfibers, (c) cement paste containing PVA microfibers and hybrid cement paste, and (d) cement paste containing CNFs, cement paste containing PVA microfibers, and hybrid cement paste for CMOD values less than $0.04 \mathrm{~mm}$ [82].

concrete structures. Although some initial studies demonstrated a higher corrosion rate of steel bars inside a CNF reinforced mortar, subjected to aggressive environments such as carbonation and chloride attack [127], more research is necessary in this direction to understand the degradation behaviour and durability of nanoreinforced concrete and the steel reinforcements present inside the concrete sections.

\section{Summary and Conclusions}

In this paper, current research activities on the carbon nanomaterial reinforced cementitious composites have been reviewed. Various dispersion techniques have been presented, and the major issues affecting the mechanical properties were discussed. It can be concluded that the dispersion of CNTs/CNFs is the main factor which controls the microstructure as well as the mechanical performance of cement nanocomposites. The conventional method of mixing nanomaterials within mortar paste using a standard mixer cannot ensure homogeneous dispersion and, therefore, deteriorates the mechanical properties. Addition of admixtures such as silica fume during the mixing process can significantly improve the nanomaterial dispersion. However, the best route to achieve homogeneous nanomaterial dispersion 
TABLE 1: Summary of different techniques used for carbon nanomaterial dispersion in cementitious matrix and resulting improvement in microstructure and mechanical properties.

\begin{tabular}{|c|c|c|c|}
\hline $\begin{array}{l}\text { Type and concentration of } \\
\text { nanomaterial }\end{array}$ & Dispersion technique $^{\mathrm{a}}$ & $\begin{array}{l}\text { Improvement in micro-structure } \\
\text { and mechanical properties }\end{array}$ & Researchers and reference \\
\hline MWCNT, 1.0 wt.\% & Ultrasonication & $\begin{array}{l}\text { Total porosity and surface area } \\
\text { decreased by } 16 \% \text { and } 23 \%\end{array}$ & Nochaiya and Chaipanich [107] \\
\hline CNT, 1.0 wt.\%, and fly ash cement & Ultrasonication & $\begin{array}{l}\text { Compressive strength improved } \\
\text { by } 10 \%\end{array}$ & Chaipanich et al. [120] \\
\hline MWCNT, 0.5 wt.\% & $\begin{array}{l}\text { Functionalization with } \\
\mathrm{HNO}_{3} / \mathrm{H}_{2} \mathrm{SO}_{4} \text { mixture and direct } \\
\text { mixing with cement }\end{array}$ & $\begin{array}{l}\text { Compressive and flexural } \\
\text { strength improved by } 19 \% \text { and } \\
25 \% \text {, total porosity reduced by } \\
64 \% \text {, and pores with diameter } \\
>50 \text { nm reduced by } 82 \%\end{array}$ & Li et al. [101] \\
\hline MWCNT, 0.5 wt.\% & $\begin{array}{l}\text { Solvent (acetone) and } \\
\text { ultrasonication }\end{array}$ & $\begin{array}{l}\text { Compressive strength improved } \\
\text { by } 11 \% \text { and } 17 \% \text { for pristine and } \\
\text { annealed CNTs }\end{array}$ & Musso et al. [112] \\
\hline Short MWCNT, 0.2 wt.\% & $\begin{array}{l}\text { Ultrasonication and } \\
\text { superplasticizer }\end{array}$ & $\begin{array}{l}\text { Flexural strength and ductility } \\
\text { improved by } 269 \% \text { and } 81 \%\end{array}$ & Al-Rub et al. [109] \\
\hline MWCNT, 0.08 wt.\% & Ultrasonication and surfactant & $\begin{array}{l}\text { Young's modulus and flexural } \\
\text { strength improved by } 45 \% \text { and } \\
25 \%\end{array}$ & Konsta-Gdoutos et al. [81] \\
\hline CNF, 0.048 wt. $\%$ & $\begin{array}{l}\text { Ultrasonication at optimum } \\
\text { conditions and surfactant }\end{array}$ & $\begin{array}{l}\text { Flexural strength and Young's } \\
\text { modulus improved by } 50 \% \text { and } \\
75 \%\end{array}$ & Metaxa et al. [110] \\
\hline MWCNT, 0.2 wt.\% & $\begin{array}{l}\text { Magnetic stirring, } \\
\text { ultrasonication, and surfactant } \\
\text { (NaDC) }\end{array}$ & $\begin{array}{l}\text { Flexural and compressive } \\
\text { strength improved by } 35.4 \% \text { and } \\
29.5 \%\end{array}$ & Luo et al. [83] \\
\hline MWCNT, 0.5 wt.\% & $\begin{array}{l}\text { Magnetic stirring, } \\
\text { ultrasonication, and } \\
\text { polycarboxylate admixture }\end{array}$ & $\begin{array}{l}\text { Compressive strength improved } \\
\text { by } 25 \%\end{array}$ & Collins et al. [90] \\
\hline MWCNT, 0.045 wt.\% & $\begin{array}{l}\text { Carboxylic functionalization, } \\
\text { ultrasonication, and polyacrylic } \\
\text { acid polymer }\end{array}$ & $\begin{array}{l}\text { Compressive strength improved } \\
\text { by } 50 \%\end{array}$ & Cwirzen et al. [86] \\
\hline Hybrid CNT-cement particle & $\begin{array}{l}\text { CNT growth onto cement } \\
\text { particles }\end{array}$ & $\begin{array}{l}\text { Compressive strength improved } \\
\text { more than } 2 \text { times }\end{array}$ & Nasibulin et al. [104] \\
\hline $\begin{array}{l}\text { CNT }(0.02 \text { wt. } \%) \text { and NMK } \\
\text { (6 wt.\%) }\end{array}$ & Dry mixing with cement & $\begin{array}{l}\text { Compressive strength improved } \\
\text { by } 11 \% \text { than mortar containing } \\
\text { NMK }\end{array}$ & Morsy et al. [121] \\
\hline $\begin{array}{l}\text { CNF ( } 0.048 \text { wt. } \%) \text { and PVA } \\
\text { micro-fibres ( } 0.54 \text { wt.\%) }\end{array}$ & Ultrasonication and surfactant & $\begin{array}{l}\text { Flexural strength, Young's } \\
\text { modulus, and toughness } \\
\text { improved by } 50 \%, 84 \% \text {, and } 33 \\
\text { times }\end{array}$ & Metaxa et al. [82] \\
\hline $\begin{array}{l}\text { CNF ( } 0.5 \text { wt.\%) and short carbon } \\
\text { fibres }\end{array}$ & $\begin{array}{l}\text { Acetone, ultrasonication, and } \\
\text { surfactant }\end{array}$ & $\begin{array}{l}\text { Load carrying capacity and } \\
\text { failure strain improved by } 54 \% \\
\text { and } 44 \%\end{array}$ & Hunashyal et al. [126] \\
\hline
\end{tabular}

is to disperse the nanomaterials first in water, followed by mixing of aqueous dispersion with mortar paste. Various chemical techniques attempted to achieve uniform and stable CNT/CNF aqueous dispersion are using surfactants, polymers, cement admixtures, functionalization, and combination of various techniques. Anionic surfactants such as SDBS, polymers such as acrylic acid, cement admixtures such as polycarboxylates, acid functionalization, and combination of functionalized nanomaterials with acrylic acid polymers were found to provide very good aqueous dispersion as well as strong enhancement in the mechanical properties of cementitious composites. Alternatively, carbon nanomaterials can be grown directly onto cement or silica fume particles to fabricate cement nanocomposites with homogeneous dispersion and significantly improved mechanical performance. Well-dispersed CNTs/CNFs lead to filling of pores within cement, improve its microstructure, restrict the propagation of nanocracks to form micro- and macrocracks, and thereby improve the fracture behaviour and mechanical properties. Hybrid cement nanocomposites containing both 
mico-fibres and nanomaterials are promising materials which show huge enhancements in both mechanical properties and fracture toughness. Although a great deal of research has been conducted in this area, research studies concerning the durability of cementitious nanocomposites are very rare. More research studies have to be carried out to understand the various characteristics related to durability of nano reinforced concrete including crack propagation and fracture behaviour, posttesting structural integrity, mechanical characterization after exposure to various degradation conditions such as freeze-thaw cycles, high temperature, chemical attack, and so forth. These studies are extremely necessary to explore the real benefits of crack-free concretes produced with carbon nanomaterials and to promote their application in construction industry.

\section{References}

[1] Y. Akkaya, S. P. Shah, and M. Ghandehari, "Influence of fiber dispersion on the performance of microfiber reinforced cement composites," American Concrete Institute, vol. 216, pp. 1-18, 2003.

[2] J. M. Makar and J. J. Beaudoin, "Carbon nanotubes and their applications in the construction industry," in Proceedings of the 1st International Symposium on Nanotechnology in Construction, pp. 331-341, Paisley, Scotland, June 2003.

[3] G. Li, "Properties of high-volume fly ash concrete incorporating nano-SiO ${ }_{2}$," Cement and Concrete Research, vol. 34, no. 6, pp. 1043-1049, 2004.

[4] Y. Qing, Z. Zenan, K. Deyu, and C. Rongshen, "Influence of nano- $\mathrm{SiO}_{2}$ addition on properties of hardened cement paste as compared with silica fume," Construction and Building Materials, vol. 21, no. 3, pp. 539-545, 2007.

[5] K. L. Lin, W. C. Chang, D. F. Lin, H. L. Luo, and M. C. Tsai, "Effects of nano- $\mathrm{SiO}_{2}$ and different ash particle sizes on sludge ash-cement mortar," Journal of Environmental Management, vol. 88, no. 4, pp. 708-714, 2008.

[6] H. Li, H.-G. Xiao, J. Yuan, and J. Ou, "Microstructure of cement mortar with nano-particles," Composites Part B, vol. 35, no. 2, pp. 185-189, 2004.

[7] H. Li, M.-H. Zhang, and J.-P. Ou, "Abrasion resistance of concrete containing nano-particles for pavement," Wear, vol. 260, no. 11-12, pp. 1262-1266, 2006.

[8] B. Han, X. Guan, and J. Ou, "Specific resistance and pressuresensitivity of cement paste admixing with nano- $\mathrm{TiO}_{2}$ and carbon fiber," Journal of the Chinese Ceramic Society, vol. 32, no. 7, pp. 884-887, 2004.

[9] G. Xiong, M. Deng, L. Xu, and M. Tang, "Properties of cementbased composites by doping nano- $\mathrm{TiO}_{2}$," Journal of the Chinese Ceramic Society, vol. 34, no. 9, pp. 1158-1161, 2006.

[10] B. Y. Lee and K. E. Kurtis, "Influence of $\mathrm{TiO}_{2}$ nanoparticles on early $\mathrm{C}_{3} \mathrm{~S}$ hydration," Journal of the American Ceramic Society, vol. 93, no. 10, pp. 3399-3405, 2010.

[11] L. Cassar, "Nanotechnology and photocatalysis in cementitious materials," in Proceedings of the 2nd International Symposium on Nanotechnology in Construction, pp. 277-683, NANOC, Bilbao, Spain, November 2005.

[12] S. J. Chen, F. G. Collins, A. J. N. Macleod, Z. Pan, W. H. Duan, and C. M. Wang, "Carbon nanotube-cement composites: a retrospect," IES Journal Part A, vol. 4, no. 4, pp. 254-265, 2011.
[13] F. Pacheco-Torgal and S. Jalali, "Nanotechnology: advantages and drawbacks in the field of construction and building materials," Construction and Building Materials, vol. 25, no. 2, pp. 582590, 2011.

[14] R. J.-M. Pellenq, A. Kushima, R. Shahsavari et al., "A realistic molecular model of cement hydrates," Proceedings of the National Academy of Sciences of the United States of America, vol. 106, no. 38, pp. 16102-16107, 2009.

[15] A. J. Allen, J. J. Thomas, and H. M. Jennings, "Composition and density of nanoscale calcium-silicate-hydrate in cement," Nature Materials, vol. 6, no. 4, pp. 311-316, 2007.

[16] P. Mondal, Nanomechanical properties of cementitious materials [Ph.D. thesis], Civil and environment engineering. Northwestern University, Evanston, Ill, USA, 2008.

[17] D. C. MacLaren and M. A. White, "Cement: its chemistry and properties," Journal of Chemical Education, vol. 80, no. 6, pp. 623-635, 2003.

[18] I. Odler, "Hydration, setting and hardening of Portland cement," in Lea's Chemistry of Cement and Concrete, pp. 241-297, Butterworth \& Heinemann, 1998.

[19] J. M. Abdoveis, An examination of concrete durability [M.S. thesis], MIT, 2003.

[20] M. Djuric, J. Ranogajec, R. Omorjan, and S. Miletic, "Sulfate corrosion of portland cement-pure and blended with $30 \%$ of fly ash," Cement and Concrete Research, vol. 26, no. 9, pp. 12951300, 1996.

[21] W. Czernin, Chemistry and Physics of Cement for Civil Engineer$s \mathrm{Co}$, Chemical Publishing, New York, NY, USA, 1962.

[22] S. D. Beyea, B. J. Balcom, T. W. Bremner et al., "The influence of shrinkage-cracking on the drying behaviour of White Portland cement using Single-Point Imaging (SPI)," Solid State Nuclear Magnetic Resonance, vol. 13, no. 1-2, pp. 93-100, 1998.

[23] H. W. Kroto, J. R. Heath, S. C. O’Brien, R. F. Curl, and R. E. Smalley, "C $\mathrm{C}_{60}$ : buckminsterfullerene," Nature, vol. 318, no. 6042, pp. 162-163, 1985.

[24] S. Iijima, "Helical microtubules of graphitic carbon," Nature, vol. 354, no. 6348, pp. 56-58, 1991.

[25] T. W. Odom, J.-L. Huang, P. Kim, and C. M. Lieber, "Structure and electronic properties of carbon nanotubes," Journal of Physical Chemistry B, vol. 104, no. 13, pp. 2794-2809, 2000.

[26] S. Rana, R. Alagirusamy, and M. Joshi, "A review on carbon epoxy nanocomposites," Journal of Reinforced Plastics and Composites, vol. 28, no. 4, pp. 461-487, 2009.

[27] R. Khare and S. Bose, "Carbon nanotube based compositesa review," Journal of Minerals \& Materials Characterization \& Engineering, vol. 4, no. 1, pp. 31-46, 2005.

[28] X.-L. Xie, Y.-W. Mai, and X.-P. Zhou, "Dispersion and alignment of carbon nanotubes in polymer matrix: a review," Materials Science and Engineering R: Reports, vol. 49, no. 4, pp. 89-112, 2005.

[29] I. Szleifer and R. Yerushalmi-Rozen, "Polymers and carbon nanotubes-dimensionality, interactions and nanotechnology," Polymer, vol. 46, no. 19, pp. 7803-7818, 2005.

[30] A. K.-T. Lau and D. Hui, "The revolutionary creation of new advanced materials-carbon nanotube composites," Composites Part B, vol. 33, no. 4, pp. 263-277, 2002.

[31] E. T. Thostenson, Z. Ren, and T.-W. Chou, "Advances in the science and technology of carbon nanotubes and their composites: a review," Composites Science and Technology, vol. 61, no. 13, pp. 1899-1912, 2001. 
[32] K. Tanaka, T. Yamabe, and K. Fukui, The Science and Technology of Carbon Nanotubes, Elsevier, Oxford, UK, 1999.

[33] P. M. Ajayan, L. S. Schadler, and P. V. Braun, Nanocomposite Science and Technology, Wiley-VCH, Weinheim, Germany, 2003.

[34] M. H. Al-Saleh and U. Sundararaj, "A review of vapor grown carbon nanofiber/polymer conductive composites," Carbon, vol. 47, no. 1, pp. 2-22, 2009.

[35] T. V. Hughes, Chambers CR. Manufacture of Carbon Filaments, US Patent 405, 1889.

[36] L. V. Radushkevich and V. M. Lukyanovich, "The structure of carbon forming in thermal decomposition of carbon monoxide on an iron catalyst," Zhurnal Fizicheskoi Khimii, vol. 26, pp. 8895, 1952.

[37] V. Z. Mordkovich, "Carbon nanofibers: a new ultrahighstrength material for chemical technology," Theoretical Foundations of Chemical Engineering, vol. 37, no. 5, pp. 429-438, 2003.

[38] B. O. Lee, W. J. Woo, and M.-S. Kim, "Mechanical properties and nanostructure of cement-based materials reinforced with carbon nanofibers and polyvinyl alcohol (PVA) microfibers," Macromolecular Materials and Engineering, vol. 286, no. 2, pp. 114-118, 2001.

[39] P. Coquay, E. Flahaut, E. De Grave, A. Peigney, R. E. Vandenberghe, and C. Laurent, "Fe/Co alloys for the catalytic chemical vapor deposition synthesis of single- and doublewalled carbon nanotubes (CNTs). 2. the CNT-Fe/Co- $\mathrm{MgAl}_{2} \mathrm{O}_{4}$ system," Journal of Physical Chemistry B, vol. 109, no. 38, pp. 17825-17830, 2005.

[40] E. Hammel, X. Tang, M. Trampert et al., "Carbon nanofibers for composite applications," Carbon, vol. 42, no. 5-6, pp. 1153-1158, 2004.

[41] C. Kuzuya, W. In-Hwang, S. Hirako, Y. Hishikawa, and S. Motojima, "Preparation, morphology, and growth mechanism of carbon nanocoils," Chemical Vapor Deposition, vol. 8, no. 2, pp. 57-62, 2002.

[42] K. Mukhopadhyay, D. Porwal, D. Lal, K. Ram, and G. N. Mathur, "Synthesis of coiled/straight carbon nanofibers by catalytic chemical vapor deposition," Carbon, vol. 42, no. 15, pp. 32543256, 2004.

[43] W. Brandl, G. Marginean, V. Chirila, and W. Warschewski, "Production and characterisation of vapour grown carbon fiber/polypropylene composites," Carbon, vol. 42, no. 1, pp. 59, 2004 .

[44] G. G. Tibbetts, M. L. Lake, K. L. Strong, and B. P. Rice, "A review of the fabrication and properties of vapor-grown carbon nanofiber/polymer composites," Composites Science and Technology, vol. 67, no. 7-8, pp. 1709-1718, 2007.

[45] H. Miyagawa, M. J. Rich, and L. T. Drzal, "Thermo-physical properties of epoxy nanocomposites reinforced by carbon nanotubes and vapor grown carbon fibers," Thermochimica Acta, vol. 442, no. 1-2, pp. 67-73, 2006.

[46] E. T. Thostenson, C. Li, and T.-W. Chou, "Nanocomposites in context," Composites Science and Technology, vol. 65, no. 3-4, pp. 491-516, 2005.

[47] T. Uchida, D. P. Anderson, M. L. Minus, and S. Kumar, "Morphology and modulus of vapor grown carbon nano fibers," Journal of Materials Science, vol. 41, no. 18, pp. 5851-5856, 2006.

[48] V. I. Merkulov, D. H. Lowndes, Y. Y. Wei, G. Eres, and E. Voelkl, "Patterned growth of individual and multiple vertically aligned carbon nanofibers," Applied Physics Letters, vol. 76, no. 24, pp. 3555-3557, 2000.
[49] M. Endo, Y. A. Kim, M. Ezaka et al., "Selective and efficient impregnation of metal nanoparticles on cup-stacked-type carbon nanofibers," Nano Letters, vol. 3, no. 6, pp. 723-726, 2003.

[50] K. D. Ausman, R. Piner, O. Lourie, R. S. Ruoff, and M. Korobov, "Organic solvent dispersions of single-walled carbon nanotubes: toward solutions of pristine nanotubes," Journal of Physical Chemistry B, vol. 104, no. 38, pp. 8911-8915, 2000.

[51] L. Vaisman, G. Marom, and H. D. Wagner, "Dispersions of surface-modified carbon nanotubes in water-soluble and waterinsoluble polymers," Advanced Functional Materials, vol. 16, no. 3, pp. 357-363, 2006.

[52] M. Bystrzejewski, A. Huczko, H. Lange, T. Gemming, B. Büchner, and M. H. Rümmeli, "Dispersion and diameter separation of multi-wall carbon nanotubes in aqueous solutions," Journal of Colloid and Interface Science, vol. 345, no. 2, pp. 138142,2010

[53] J. I. Paredes and M. Burghard, "Dispersions of individual singlewalled carbon nanotubes of high length," Langmuir, vol. 20, no. 12, pp. 5149-5152, 2004.

[54] J. Pang, G. Xu, S. Yuan, Y. Tan, and F. He, "Dispersing carbon nanotubes in aqueous solutions by a silicon surfactant: experimental and molecular dynamics simulation study," Colloids and Surfaces A, vol. 350, no. 1-3, pp. 101-108, 2009.

[55] H. Peng, L. B. Alemany, J. L. Margrave, and V. N. Khabashesku, "Sidewall carboxylic acid functionalization of single-walled carbon nanotubes," Journal of the American Chemical Society, vol. 125, no. 49, pp. 15174-15182, 2003.

[56] Y. Wang, Z. Iqbal, and S. V. Malhotra, "Functionalization of carbon nanotubes with amines and enzymes," Chemical Physics Letters, vol. 402, no. 1-3, pp. 96-101, 2005.

[57] Y. V. Lavskaya, L. G. Bulusheva, A. V. Okotrub, N. F. Yudanov, D. V. Vyalikh, and A. Fonseca, "Comparative study of fluorinated single- and few-wall carbon nanotubes by X-ray photoelectron and X-ray absorption spectroscopy," Carbon, vol. 47, no. 7, pp. 1629-1636, 2009.

[58] A. Felten, C. Bittencourt, J. J. Pireaux, G. Van Lier, and J. C. Charlier, "Radio-frequency plasma functionalization of carbon nanotubes surface $\mathrm{O}_{2}, \mathrm{NH}_{3}$, and $\mathrm{CF}_{4}$ treatments," Journal of Applied Physics, vol. 98, no. 7, Article ID 074308, 2005.

[59] Z. N. Utegulov, D. B. Mast, P. He, D. Shi, and R. F. Gilland, "Functionalization of single-walled carbon nanotubes using isotropic plasma treatment: resonant Raman spectroscopy study," Journal of Applied Physics, vol. 97, no. 10, Article ID 104324, pp. 1-4, 2005.

[60] Y. Wang, Z. Iqbal, and S. Mitra, "Rapidly functionalized, waterdispersed carbon nanotubes at high concentration," Journal of the American Chemical Society, vol. 128, no. 1, pp. 95-99, 2006.

[61] J. M. Gonzalez-Dominguez, Y. Martınez-Rubi, M. Diez-Pascual et al., "Reactive fillers based on SWCNTs functionalized with matrix-based moieties for the production of epoxy composites with superior and tunable properties," Nanotechnology, vol. 23, no. 28, Article ID 285702, 2012.

[62] J. U. Lee, J. Huh, K. H. Kim, C. Park, and W. H. Jo, “Aqueous suspension of carbon nanotubes via non-covalent functionalization with oligothiophene-terminated poly(ethylene glycol)," Carbon, vol. 45, no. 5, pp. 1051-1057, 2007.

[63] X. Xin, G. Xu, T. Zhao et al., "Dispersing carbon nanotubes in aqueous solutions by a starlike block copolymer," Journal of Physical Chemistry C, vol. 112, no. 42, pp. 16377-16384, 2008.

[64] E. Nativ-Roth, R. Shvartzman-Cohen, C. Bounioux et al., "Physical adsorption of block copolymers to SWNT and 
MWNT: a nonwrapping mechanism," Macromolecules, vol. 40, no. 10, pp. 3676-3685, 2007.

[65] R. Haggenmueller, S. S. Rahatekar, J. A. Fagan et al., "Comparison of the quality of aqueous dispersions of single wall carbon nanotubes using surfactants and biomolecules," Langmuir, vol. 24, no. 9, pp. 5070-5078, 2008.

[66] Y. Sabba and E. L. Thomas, "High-concentration dispersion of single-wall carbon nanotubes," Macromolecules, vol. 37, no. 13, pp. 4815-4820, 2004.

[67] J. Zhu, M. Yudasaka, M. Zhang, and S. Iijima, "Dispersing carbon nanotubes in water: a noncovalent and nonorganic way," Journal of Physical Chemistry B, vol. 108, no. 31, pp. 11317-11320, 2004.

[68] P. C. Ma, J.-K. Kim, and B. Z. Tang, "Effects of silane functionalization on the properties of carbon nanotube/epoxy nanocomposites," Composites Science and Technology, vol. 67, no. 14, pp. 2965-2972, 2007.

[69] N. G. Sahoo, Y. C. Jung, H. J. Yoo, and J. W. Cho, "Effect of functionalized carbon nanotubes on molecular interaction and properties of polyurethane composites," Macromolecular Chemistry and Physics, vol. 207, no. 19, pp. 1773-1780, 2006.

[70] S.-M. Yuen, C.-C. M. Ma, Y.-Y. Lin, and H.-C. Kuan, "Preparation, morphology and properties of acid and amine modified multiwalled carbon nanotube/polyimide composite," Composites Science and Technology, vol. 67, no. 11-12, pp. 2564-2573, 2007.

[71] A. A. Koval'chuk, V. G. Shevchenko, A. N. Shchegolikhin, P. M. Nedorezova, A. N. Klyamkina, and A. M. Aladyshev, "Effect of carbon nanotube functionalization on the structural and mechanical properties of polypropylene/MWCNT composites," Macromolecules, vol. 41, no. 20, pp. 7536-7542, 2008.

[72] M. T. Byrne, W. P. McNamee, and Y. K. Gun'ko, "Chemical functionalization of carbon nanotubes for the mechanical reinforcement of polystyrene composites," Nanotechnology, vol. 19, no. 41, Article ID 415707, 2008.

[73] K. H. Kim and W. H. Jo, "Improvement of tensile properties of poly(methyl methacrylate) by dispersing multi-walled carbon nanotubes functionalized with poly(3-hexylthiophene)-graftpoly(methyl methacrylate)," Composites Science and Technology, vol. 68, no. 9, pp. 2120-2124, 2008.

[74] Y.-H. Liao, O. Marietta-Tondin, Z. Liang, C. Zhang, and B. Wang, "Investigation of the dispersion process of SWNTs/SC-15 epoxy resin nanocomposites," Materials Science and Engineering A, vol. 385, no. 1-2, pp. 175-181, 2004.

[75] K. Gopalakrishnan, B. Birgisson, P. Taylor, and N. O. AttohOkine, Nanotechnology in Civil InfrAstructure a paradigm Shift, Springer, Heidelberg, Germany, 2011.

[76] F. P. Cota, T. H. Panzera, M. A. Schiavon et al., "Full factorial design analysis of carbon nanotube polymer-cement composites," Materials Research, vol. 15, no. 4, pp. 573-580, 2012.

[77] A. Yazdanbakhsh, Z. C. Grasley, B. Tyson, and R. K. Abu AlRub, "Carbon nano filaments in cementitious materials: Some issues on dispersion and interfacial bond," in ACI Fall 2009 Convention, pp. 31-34, November 2009.

[78] A. Yazdanbakhsh, Z. Grasley, B. Tyson, and R. K. Abu AlRub, "Distribution of carbon nanofibers and nanotubes in cementitious composites," Transportation Research Record, no. 2142, pp. 89-95, 2010.

[79] D. P. Bentz, E. J. Garboczi, C. J. Haecker, and O. M. Jensen, "Effects of cement particle size distribution on performance properties of Portland cement-based materials," Cement and Concrete Research, vol. 29, no. 10, pp. 1663-1671, 1999.
[80] A. Yazdanbakhsh and Z. Grasley, "The theoretical maximum achievable dispersion of nanoinclusions in cement paste," Cement and Concrete Research, vol. 42, no. 6, pp. 798-804, 2012.

[81] M. S. Konsta-Gdoutos, Z. S. Metaxa, and S. P. Shah, "Highly dispersed carbon nanotube reinforced cement based materials," Cement and Concrete Research, vol. 40, no. 7, pp. 1052-1059, 2010.

[82] Z. S. Metaxa, M. S. Konsta-Gdoutos, and S. P. Shah, "Mechanical properties and nanostructure of cement-based materials reinforced with carbon nanofibers and Polyvinyl Alcohol (PVA) microfibers," in ACI Spring 2010 Convention, pp. 115-126, March 2010.

[83] J. Luo, Z. Duan, and H. Li, "The influence of surfactants on the processing of multi-walled carbon nanotubes in reinforced cement matrix composites," Physica Status Solidi A, vol. 206, no. 12, pp. 2783-2790, 2009.

[84] M. F. Islam, E. Rojas, D. M. Bergey, A. T. Johnson, and A. G. Yodh, "High weight fraction surfactant solubilization of singlewall carbon nanotubes in water," Nano Letters, vol. 3, no. 2, pp. 269-273, 2003.

[85] X. Yu and E. Kwon, "A carbon nanotube/cement composite with piezoresistive properties," Smart Materials and Structures, vol. 18, no. 5, Article ID 055010, 2009.

[86] A. Cwirzen, K. Habermehl-Cwirzen, and V. Penttala, "Surface decoration of carbon nanotubes and mechanical properties of cement/carbon nanotube composites," Advances in Cement Research, vol. 20, no. 2, pp. 65-73, 2008.

[87] V. P. Veedu, Multifunctional cementitious nanocomposite material and methods of making the same, Patent: US, 7666327 B1, 2010.

[88] F. Azhari, Cement-Based Sensors for Structural Health Monitoring. Dissertation for the Master Degree of Applied Science, University of British Columbia, Vancouver, Canada, 2008.

[89] F. Azhari and N. Banthia, "Structural health monitoring using piezoresistive cementitious composites," in Proceedings of the 2nd International Conference on Sustainable Construction Materials and Technologies, Ancona, Italy, June.

[90] F. Collins, J. Lambert, and W. H. Duan, "The influences of admixtures on the dispersion, workability, and strength of carbon nanotube-OPC paste mixtures," Cement and Concrete Composites, vol. 34, no. 2, pp. 201-207, 2012.

[91] R. Rixom and N. Mailvaganam, Chemical Admixtures Handbook for Concreteed, E \& FN Spon, London, UK, 3rd edition, 1999.

[92] D. D. L. Chung, "Improving cement-based materials by using silica fume," Journal of Materials Science, vol. 37, no. 4, pp. 673682, 2002.

[93] A. M. Neville, Properties of Concrete, Pearson Education Limited, New York, NY, USA, 2005.

[94] D. P. Bentz, O. M. Jensen, A. M. Coats, and F. P. Glasser, "Influence of silica fume on diffusivity in cement-based materials. I. Experimental and computer modeling studies on cement pastes," Cement and Concrete Research, vol. 30, no. 6, pp. 953$962,2000$.

[95] H. Toutanji, S. McNeil, and Z. Bayasi, "Chloride permeability and impact resistance of polypropylene-fiber-reinforced silica fume concrete," Cement and Concrete Research, vol. 28, no. 7, pp. 961-968, 1998.

[96] D. D. L. Chung, "Dispersion of short fibers in cement," Journal of Materials in Civil Engineering, vol. 17, no. 4, pp. 379-383, 2005. 
[97] F. Sanchez and C. Ince, "Microstructure and macroscopic properties of hybrid carbon nanofiber/silica fume cement composites," Composites Science and Technology, vol. 69, no. 7-8, pp. 1310-1318, 2009.

[98] F. Sanchez, "Carbon nanofiber/cement composites: challenges and promises as structural materials," International Journal of Materials and Structural Integrity, vol. 3, no. 2-3, pp. 217-226, 2009.

[99] G. Y. Li, P. M. Wang, and X. Zhao, "Pressure-sensitive properties and microstructure of carbon nanotube reinforced cement composites," Cement and Concrete Composites, vol. 29, no. 5, pp. 377-382, 2007.

[100] F. Sanchez, L. Zhang, and C. Ince, "Multi-scale performance and durability of carbon nanofiber/cement composites," in Proceedings of the 3rd International Symposium on Nanotechnology in Construction, vol. 3, pp. 345-350, 2009.

[101] G. Y. Li, P. M. Wang, and X. Zhao, "Mechanical behavior and microstructure of cement composites incorporating surfacetreated multi-walled carbon nanotubes," Carbon, vol. 43, no. 6 , pp. 1239-1245, 2005.

[102] L. I. Nasibulina, I. V. Anoshkin, A. G. Nasibulin, A. Cwirzen, V. Penttala, and E. I. Kauppinen, "Effect of carbon nanotube aqueous dispersion quality on mechanical properties of cement composite," Journal of Nanomaterials, vol. 2012, Article ID 169262, 2012.

[103] B. Han, K. Zhang, X. Yu, E. Kwon, and J. Ou, "Electrical characteristics and pressure-sensitive response measurements of carboxyl MWNT/cement composites," Cement and Concrete Composites, vol. 34, no. 6, pp. 794-800, 2012.

[104] A. G. Nasibulin, S. D. Shandakov, L. I. Nasibulina et al., "A novel cement-based hybrid material," New Journal of Physics, vol. 11, Article ID 023013, 2009.

[105] P. R. Mudimela, L. I. Nasibulina, A. G. Nasibulin et al., "Synthesis of carbon nanotubes and nanofibers on silica and cement matrix materials," Journal of Nanomaterials, vol. 2009, Article ID 526128, 2009.

[106] Z. S. Metaxa, J.-W. T. Seo, M. S. Konsta-Gdoutos, M. C. Hersam, and S. P. Shah, "Highly concentrated carbon nanotube admixture for nano-fiber reinforced cementitious materials," Cement and Concrete Composites, vol. 34, no. 5, pp. 612-617, 2012.

[107] T. Nochaiya and A. Chaipanich, "Behavior of multi-walled carbon nanotubes on the porosity and microstructure of cementbased materials," Applied Surface Science, vol. 257, no. 6, pp. 1941-1945, 2011.

[108] J. Makar, J. Margeson, and J. Luh, "Carbon nanotube/cement composites-early results and potential applications," in Proceedings of the 3rd International Conference on Construction Materials: Performance, Innovations and Structural Implications, Vancouver, Canada, 2005.

[109] R. K. A. Al-Rub, A. I. Ashour, and B. M. Tyson, "On the aspect ratio effect of multi-walled carbon nanotube reinforcements on the mechanical properties of cementitious nanocomposites," Construction and Building Materials, vol. 35, pp. 647-655, 2012.

[110] Z. S. Metaxa, M. S. Konsta-Gdoutos, and S. P. Shah, "Carbon nanofiber cementitious composites: effect of debulking prollcedure on dispersion and reinforcing efficiency," Cement and Concrete Composites, vol. 36, pp. 25-32, 2013.

[111] A. Yazdanbakhsh, Z. Grasley, B. Tyson, and R. A. Al-Rub, "Challenges and benefits of utilizing carbon nanofilaments in cementitious materials," Journal of Nanomaterials, vol. 2012, Article ID 371927, 8 pages, 2012.
[112] S. Musso, J.-M. Tulliani, G. Ferro, and A. Tagliaferro, "Influence of carbon nanotubes structure on the mechanical behavior of cement composites," Composites Science and Technology, vol. 69, no. 11-12, pp. 1985-1990, 2009.

[113] G. Yakovlev, J. Kerienè, A. Gailius, and I. Girnienè, "Cement based foam concrete reinforced by carbon nanotubes," Materials Science, vol. 12, no. 2, pp. 147-151, 2006.

[114] B. W. Langan, K. Weng, and M. A. Ward, "Effect of silica fume and fly ash on heat of hydration of Portland cement," Cement and Concrete Research, vol. 32, no. 7, pp. 1045-1051, 2002.

[115] V. Saraswathy and H.-W. Song, "Evaluation of corrosion resistance of Portland pozzolana cement and fly ash blended cements in pre-cracked reinforced concrete slabs under accelerated testing conditions," Materials Chemistry and Physics, vol. 104, no. 2-3, pp. 356-361, 2007.

[116] T. Yen, T.-H. Hsu, Y.-W. Liu, and S.-H. Chen, "Influence of class F fly ash on the abrasion-erosion resistance of high-strength concrete," Construction and Building Materials, vol. 21, no. 2, pp. 458-463, 2007.

[117] J. Zuquan, S. Wei, Z. Yunsheng, J. Jinyang, and L. Jianzhong, "Interaction between sulfate and chloride solution attack of concretes with and without fly ash," Cement and Concrete Research, vol. 37, no. 8, pp. 1223-1232, 2007.

[118] J. M. Miranda, A. Fernández-Jiménez, J. A. González, and A. Palomo, "Corrosion resistance in activated fly ash mortars," Cement and Concrete Research, vol. 35, no. 6, pp. 1210-1217, 2005.

[119] H. Yazici, “The effect of silica fume and high-volume Class C fly ash on mechanical properties, chloride penetration and freezethaw resistance of self-compacting concrete," Construction and Building Materials, vol. 22, no. 4, pp. 456-462, 2008.

[120] A. Chaipanich, T. Nochaiya, W. Wongkeo, and P. Torkittikul, "Compressive strength and microstructure of carbon nanotubes-fly ash cement composites," Materials Science and Engineering A, vol. 527, no. 4-5, pp. 1063-1067, 2010.

[121] M. S. Morsy, S. H. Alsayed, and M. Aqel, "Hybrid effect of carbon nanotube and nano-clay on physico-mechanical properties of cement mortar," Construction and Building Materials, vol. 25, no. 1, pp. 145-149, 2011.

[122] S. Wild, J. M. Khatib, and A. Jones, "Relative strength, pozzolanic activity and cement hydration in superplasticised metakaolin concrete," Cement and Concrete Research, vol. 26, no. 10, pp. 1537-1544, 1996.

[123] T. R. Jones, G. V. Walters, and J. A. Kostuch, "Role of metakaolin in suppressing ASR in concrete containing reactive aggregate and exposed to saturated $\mathrm{NaCl}$ solution," in Proceedings of the 9th International Conference Alkali-Aggregate Reaction Concrete, vol. 1, pp. 485-496, 1992.

[124] J. M. Khatib and S. Wild, "Sulphate resistance of metakaolin mortar," Cement and Concrete Research, vol. 28, no. 1, pp. 8392, 1998.

[125] A. Dubey and N. Banthia, "Influence of high-reactivity metakaolin and silica fume on the flexural toughness of highperformance steel fiber-reinforced concrete," ACI Materials Journal, vol. 95, no. 3, pp. 284-292, 1998.

[126] A. M. Hunashyal, S. J. Lohitha, S. S. Quadri, and N. R. Banapurmath, "Experimental investigation of the effect of carbon nanotubes and carbon fibres on the behaviour of plain cement composite beams," IES Journal Part A, vol. 4, no. 1, pp. 29-36, 2011. 
[127] O. Galao, E. Zornoza, F. J. Baeza, A. Bernabeu, and P. Garces, "Effect of carbon nanofiber addition in the mechanical properties and durability of cementitious materials," Materiales de Construcción, vol. 62, no. 307, pp. 343-357, 2012. 

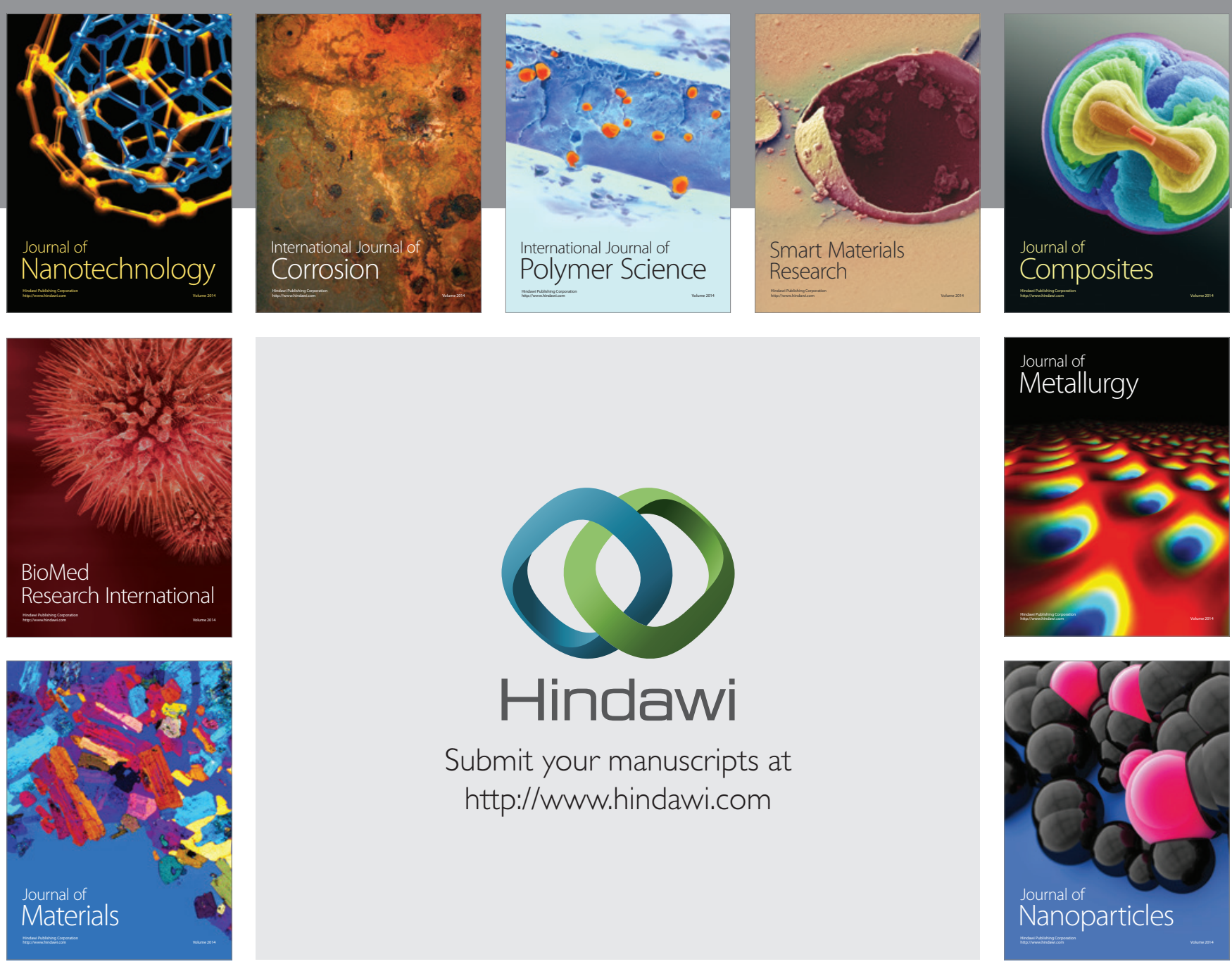

Submit your manuscripts at http://www.hindawi.com
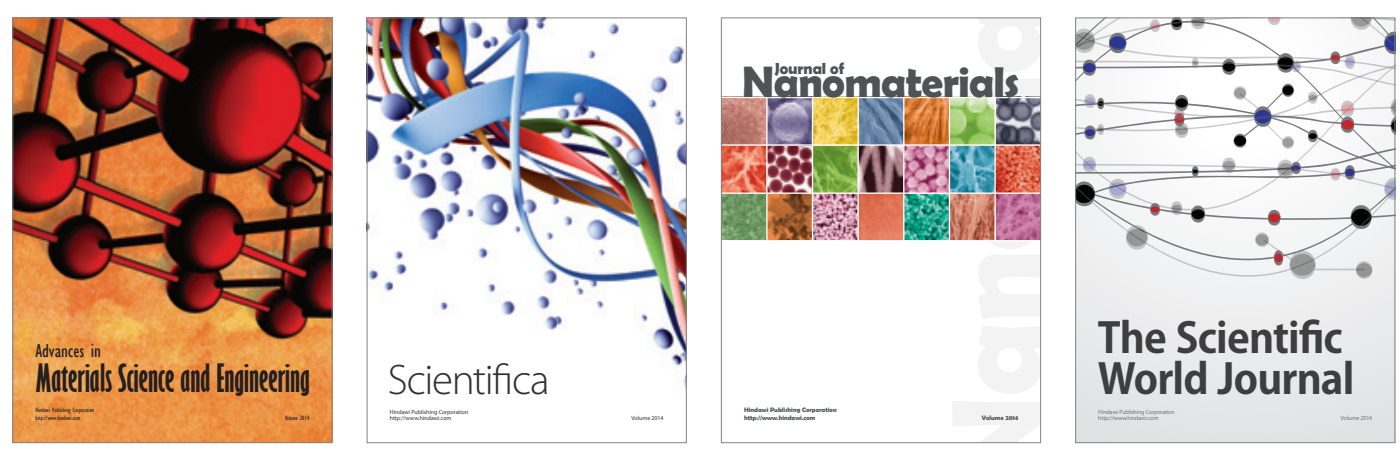

\section{The Scientific World Journal}
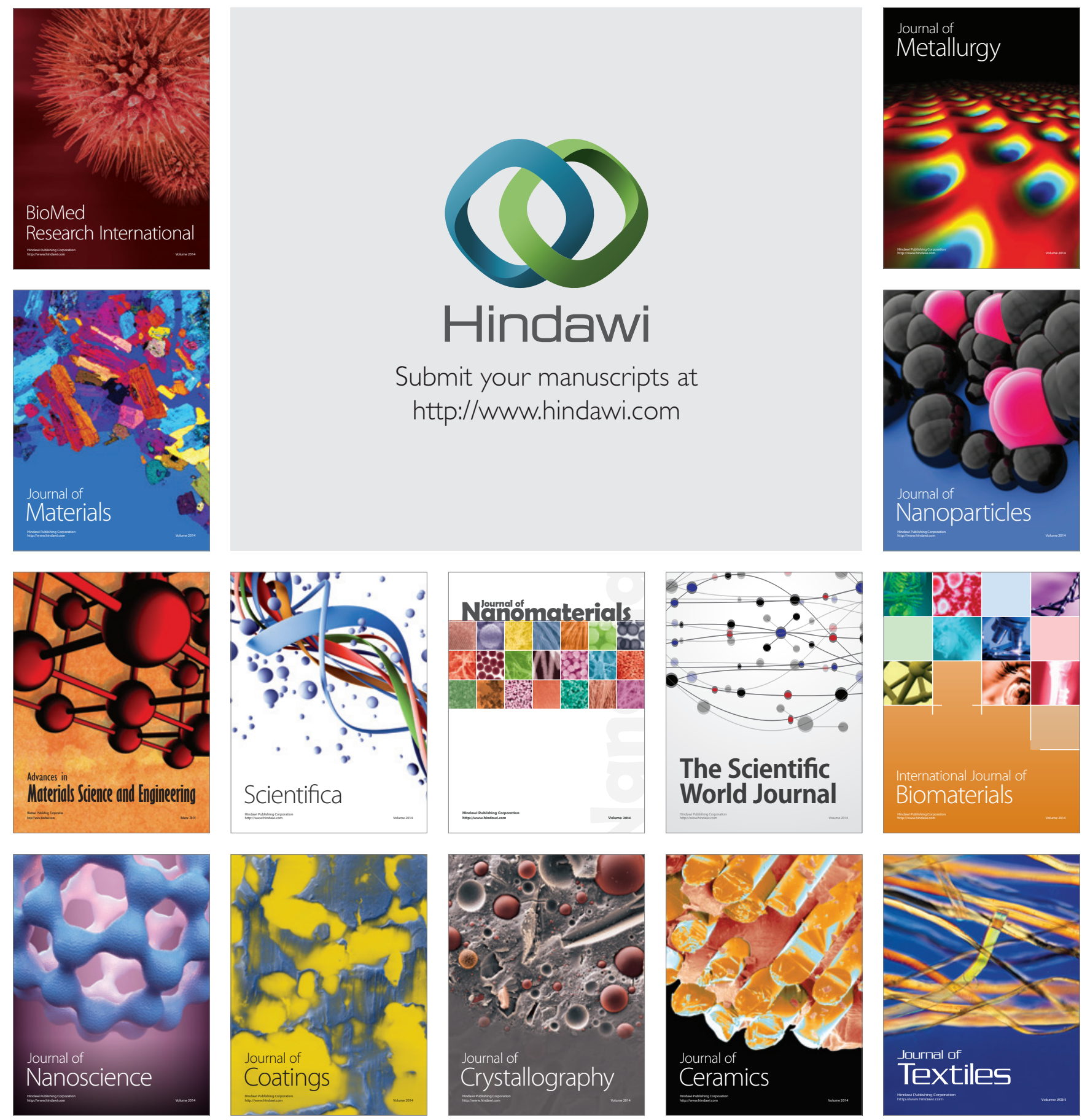